\title{
Epistemología, controversias y pragmática
}

\author{
MARCELO DASCAL \\ Universidad de Tel Aviv
}

En este artículo quiero presentar y defender la tesis de que el impasse en que se encuentran la epistemología y la historia de la ciencia desde hace un par de décadas se debe, en gran parte, o bien a la total ignorancia, o bien al tratamiento equivocado del rol jugado por las controversias científicas en la evolución de la ciencia.

Para hacerlo, tendré que empezar por una aclaración preliminar del impasse a que me refiero (sección 1). Luego, explicaré por qué veo en el estudio de las controversias científicas una pieza fundamental para solucionarlo (sección 2), identificaré la posición de dichas controversias en el seno del conjunto de los fenómenos empíricos del tipo 'discurso polémico' (sección 3) e indicaré las propiedades de tales controversias que explican su rol potencial para solventar el impasse (sección 4). Pasaré enseguida a mostrar el modo en que las opciones epistemológicas exis- tentes son incapaces de tratar las controversias de manera satisfactoria, lo que explica su incapacidad para reśolver el impasse (sección 5). Más adelante expondré un desideratum esencial para resolver ese impasse (sección 6), e indicaré de qué manera cabe satisfacerlo empleando la pragmática como instrumento y como modelo (sección 7 ).

Lo que se me antojó, en un principio, tn artículo relativamente corto, se ha ido transformando progresivamente en un texto complejo y extenso, más digno de un ensayo. He tratado de acortarlo, reduciéndolo a lo esencial. De ahí que algunas afirmaciones puedan parecer dogmáticas e insuficientemente fundamentadas. Espero cumplir con el onus probandi que me compete llevar a cabo en el prometido ensayo. Pero no quise dejar de publicar su esbozo en estas reflexiones, para poder -cuando menos así lo espero- beneficiarme de la crítica.

\section{El impasse ${ }^{1}$}

Tomo como punto de partida el fracaso (admitido más o menos universalmente) de la filosofía de la ciencia lógico-positivista. Según sus críticos, esa filosofía ha fracasado tanto en el plano normativo como en el descriptivo.

En el plano normativo, porque su noción principal, la de 'justificación' de una teoría, es insostenible, al ser esencialmente inductivista y estar basada en la noción de 'confirmación'. Según Popper, principal crítico del componente normativo del modelo positivista, no es posible construir una lógica inductiva capaz. de formalizar satisfactoriamente la idea de que se 
puede adjudicar a cada teoría un 'grado de confirmación' en términos de su probabilidad condicional relativa a los datos disponibles. Si se insiste en emplear esa noción, el resultado es que todas las teorías tendrán, a lo sumo, un grado de confirmación idéntico $(=$ cero), lo que hace imposible derivar de esa noción un criterio para la aceptación o rechazo de una teoría. El criterio normativo alternativo que propone Popper se basa - como se sabe- en la refutabilidad y no en la confirmabilidad de las teorías cientificas. Toda teoría científica es considerada como una conjetura refutable. Se 'aceptan' las teorías que han sobrevivido a esfuerzos 'serios' por refutarlas. Ese criterio contiene, pues, no sólo un principio para evaluar teorías, sino también una recomendación normativa para la acción de los científicos: éstos tienen, por una parte, que producir conjeturas refutables y, por otra, esforzarse por refutar las conjeturas, ya sean propias o ajenas; además tienen que estar dispuestos a abandonar una teoría, por muy cara que les resulte, una vez que ha sido refutada.

En el plano descriptivo, la crítica al positivismo ha consistido en señalar que el 'crecimiento del saber' científico no tiene lugar en virtud de incrementos sucesivos del grado de confirmación de las teorías propuestas, como haría suponer el modelo positivista. Críticos como Kuhn, apoyándose en la historia de la ciencia, arguyen que, a lo sumo, esa concepción del progreso científico se aplica a ciertos periodos relativamente homogéneos de 'ciencia normal'. Pero esos períodos se interrumpen bruscamente por 'crisis' o rupturas radicales en la evolución de la ciencia, rupturas que no permiten siquiera comparar -ni mucho menos calibrar- el progreso efectuado entre un período normal y otro. El 'crecimiento del saber' -si es que existe- se produce, por lo tanto, no en forma lineal o progresiva, sino más bien' en zig-zag, y se caracteriza por una 'inconmensurabilidad' profunda entre sus etapas, que afecta incluso a las mismas normas metodológicas.

Críticos aún más radicales, como Feyerabend, arguyen que, aun en los periodos 'normales', los científicos son de hecho 'oportunistas' metodológicos, que se sirven de todos los métodos disponibles para defender sus teorías, sin jurar fidelidad absoluta a ninguno. De esta forma, se cuestiona no solamente la norma positivista, sino de hecho cualquier metodología normativa, incluyendo, evidentemente, la del mismo Popper. El resultado al que lleva este tipo de crítica es la negación de la posibilidad de elaborar criterios universales de legitimación del conocimiento científico, es decir, criterios basados exclusivamente en principios de racionalidad. En última instancia, se trata de abandonar el proyecto mismo de elaboración de una 'epistemología', es decir, una teoría capaz de justificar los modos válidos de conocimiento y no sólo de describir los modos considerados válidos por una u otra comunidad, cultura, o período histórico.

Las dos fases del fracaso positivista, la normativa y la descriptiva, se 
hallan íntimamente conectadas. Los propios argumentos de sus críticos descriptivistas y normativistas así lo muestran: los primeros señalan la inutilidad de normas que nadie sigue, así como las variaciones históricas en esas normas; los segundos, la necesidad de adoptar normas que tengan alguna adecuación descriptiva, pero sin caer en el inevitable relativismo del descriptivismo puro, que haría imposibile explicar la 'racionalidad' del progreso científico. Por consiguiente, en la filosofia de la ciencia post-positivista, donde "the descriptive and the normative are inextricably mixed» (Kuhn 1970: 233), las posiciones no se ordenan ya simplemente según las categorías normativo/descriptivo, sino según la manera como se combinan y subordinan mutuamente. Cuando Lakatos (1970:177) describe su diferencia con Kuhn diciendo que «Kuhn's conceptual framework for dealing with continuity in science is socio-psychological: mine is normatives (provocando vehementes protestas por parte de Kuhn), sin duda exagera la polarización en aras de la retórica. Al fin y al cabo, él mismo subraya a renglón seguido la palabra 'también': "Where Kuhn sees 'paradigms', I also see rational 'research programmes'» (ibid.). Asimismo, alienta la necesidad de dar cuenta de la interacción entre los 'tres mundos' popperianos (Lakatos 1970: 180), y en otro texto subraya la necesidad de explicar show the historiography of science should learn from the philosophy of science and vice-versa» (Lakatos 1981: 107). ${ }^{2}$

El problema que se plantea, por lo tanto, no es el de elegir entre normativismo y descriptivismo, sino más bien el de encontrar una forma satisfactoria de combinarlos, a la luz de sus críticas recíprocas. El impasse en que se encuentran la filosolía y la historia de la ciencia tiene su origen en el hecho de que las combinaciones propuestas hasta ahora tienden a subordinar excesivamente uno de esos componentes al otro, sin armonizarlos realmente.

El camino propuesto por Lakatos en su "metodología de los programas de investigación científicos» trata de tomar en cuenta la dimensión histórica y, sobre todo, el hecho de que en la mayor parte de los casos las teorías se resisten a la 'muerte instantánea' que su 'refutación' empírica tendría supuestamente que causar (según la posición que Lakatos denomina "falsacionismo ingenuo"). Su preocupación central es la de justificar racionalmente ese hecho. O sea, mostrar de qué manera la violación frecuente de lo que parece ser una norma fundamental de la actividad científica puede ser comprendida en los términos de un concepto más amplio y profundo de racionalidad. La solución consiste en no tomar teorías aisladas como si fueran las unidades que cabe someter a evaluación racional, sino hacer lo propio con series de teorías - 'programas de investigación'guiadas por principios comunes. La historicidad se transforma así en algo esencial para la aplicación de la norma de racionalidad. Sin embargo, para cumplir con esa función, tiene que tratarse - según Lakatos- de una his- 
toricidad 'interna', basada en la 'reconstrucción racional' de la serie de teorías, de la cual se descartan de antemano factores 'externos' considerados no pertinentes. El ojo normativo de la 'filosofía' es el que determina la selección de lo pertinente, mientras que el ojo descriptivo de la historia (o de la sociología, psicología, etc.) le sirve a lo sumo de auxiliar. No es de sorprender, por lo tanto, que para Lakatos el drama de la evolución de la ciencia transcurra no en la historia real, sino en el 'tercer mundo', donde impera la normatividad, y que sus personajes no sean los sujetos cognoscentes, sino el 'conocimiento articulado', independiente de ellos. ${ }^{3} \mathrm{~A}$ mi entender, Lakatos en ningún momento satisface su propia exigencia de elaborar una teoría del crecimiento del conocimiento realmente capaz de integrar los tres mundos.

Tampoco lo hace el descriptivismo en sus variantes conocidas. La ambivalencia entre prescripción y descripción que detecta Feyerabend (1970: 198) en la obra de Kuhn se limita a confirmar que también aquí se da una preocupación por combinar los dos componentes. Y sin duda tiene razón Kuhn (1970: 237), al contestarle que su obra tiene que ser leída de ambas maneras al mismo tiempo. Pero su argumento a tal efecto -que él considera simple e inobjetable - - revela claramente la prioridad que atribuye a lo descriptivo y la consecuente naturaleza 'débil' de la normatividad que permite: ${ }^{4}$

a) Los científicos actúan de cierta manera.

b) Esa manera de actuar cumple ciertas funciones esenciales.

c) No hay otra manera de actuar que cumpla las mismas funciones.

d) Los científicos desean mejorar el conocimiento científico.

Ergo:

e) Los científicos deben actuar como actúan.

Sin duda hay en este argumento una premisa deóntica $(d)$ que permite dar desde un punto de vista formal, y sin cometer la llamada "falacia naturalista', el paso a la conclusión normativa (e). Sin embargo, se trata de una normatividad 'débil', aplicable solamente bajo la condición (c). Pero esa condición es satisfecha tan sólo en el seno de un paradigma: los científicos entrenados en él simplemente son incapaces de discernir otras formas 'científicas' de actuar. Mas, según el propio Kuhn, un cambio de paradigma acarrea, entre otras cosas, un cambio en las 'maneras de actuar' que les parecen a los científicos conducir al 'Florecimiento de su empresa'. $\mathrm{O}$ sea, que con el cambio de paradigma surgen necesariamente otras formas de actuar capaces de cumplir las 'funciones esenciales' de la ciencia, tales como son percibidas dentro de cada paradigma. Es decir, que el 'deber actuar como actúan' adquiere diferentes contenidos con cada cambio de paradigma, sin que sea posible justificarlo o criticarlo más que internamente'. La conclusión normativa (e) es 'débil' porque, siendo la condición 
(c), o bien trivialmente verdadera (dentro de un paradigma) o bien falsa (trans-paradigmáticamente), no disponemos de ningún criterio que permita realmente comparar 'formas de actuar' distintas y, por ende, de atribuirles una normatividad más 'fuerte', es decir, fundada en criterios que se apliquen, aunque no universalmente, por lo menos más allá de los límites de cada período de 'ciencia normal'.6

La separación estricta que hace Kuhn entre los periodos de 'ciencia normal', donde reina una normatividad rigurosa, y los de 'ciencia extraordinaria', en que se suspende prácticamente la normatividad y anything goes, es sintomática de la dificultad que tiene su proyecto en armonizar los dos componentes. El descriptivismo más radical, sea historiográfico, sociológico, o psicológico, tiende a su vez a renunciar totalmente al componente normativo, contentándose con ofrecer descripciones o, a lo sumo, análisis causales. De esa forma es llevado - paradójicamente- a una especie de 'positivismo' (en el sentido en que se emplea esa palabra en filosofía del derecho): el único criterio de 'validez' de las normas es su existencia, y su aceptación y evolución sólo pueden ser explicadas en términos de procesos o fuerzas 'externas' que actúan como causas, mas no como razones.?

Si las teorias vigentes se han mostrado incapaces de armonizar una racionalidad normativa con la descripción de los hechos de la praxis científica, es porque no han sabido acercar la una a la otra. Tanto el descriptivismo como el normativismo han aceptado, sin cuestionarla, la oposición y consecuente separación entre una racionalidad de carácter regulativo o formal y una descriptividad que, aunque a veces se declare reconstructiva, sirva para captar los hechos en su estado bruto, por decirlo asi, o sea, en una fase anterior a cualquier normatividad. Ese enajenamiento mutuo es el que impide encontrar un punto de contacto entre ambas. ${ }^{8}$

Lo que se necesita para superar ese impasse es sobreponerse a la oposición que lo engendra. Se trata, por una parte, de hacer bajar a la racionalidad de sus alturas regulativas, haciéndola constitutiva de contenidos y sensible al contexto de su aplicación, aun si eso acarrea el peligro de su 'contaminación' por la contingencia y una consecuente renuncia a pretensiones universalistas. Por otra parte, se trata de reconocer que la praxis científica, en cuanto actividad humana guiada por razones, no puede ser descrita en términos enteramente ajenos al papel constitutivo de esas razones. A mi entender, es la posibilidad de ese doble movimiento de acercamiento entre norma y descripción, entre racionalidad y 'realidad', lo que hay que demostrar. Estoy convencido de que el punto de convergencia par excellence donde ocurre ese encuentro es la controversia científica. Lo que cabe hacer, por lo tanto, es comprender por qué la controversia científica es imposible según las teorias vigentes, y tratar de construir un argumento que demuestre su posibilidad. Antes de hacerlo, debo explicar por qué me parece tan crucial el papel de las controversias y cómo las concibo. 


\section{Por qué controversias}

TESIS A: Las controversias son indispensables para la formación, evolución y evaluación de las teorras (científicas), porque es en ellas donde se ejerce la crítica 'seria', es decir, aquella que permite engendrar, mejorar y controlar, ya sea la 'buena estructuración', ya sea el 'contenido empírico' de las teorias cientificas.

Se observa de inmediato en esta tesis un elemento común con el nomativismo popperiano: la importancia que atribuyo a la crítica. Creo que ese punto de partida es razonable y no trataré de defenderlo aquí. Partiendo de él, lo esencial es tratar de estudiar y comprender las condiciones de posibilidad de la crítica. A diferencia de Popper, que considera esas condiciones como pertenecientes exclusivamente al plano lógico, considero indispensable tomar en cuenta también las condiciones posibilitadoras de esa actividad crítica que se ejerce sobre todo en las controversias. En éstas se oponen, no observaciones a conjeturas, ni teorías a teorias, ni argumentos a argumentos, ni siquiera programas de investigación a programas de investigación, sino científicos que realizan experimentos y observaciones, formulan teorias y argumentos, y persisten en sus programas de investigación o los abandonan - todo eso frente a científicos que se oponen a los primeros ejecutando los mismos tipos de actividad. Conceptos como los de 'seriedad' (Popper) o 'tenacidad' (Lakatos), esenciales para que la crítica cumpla su función según los normativistas, se aplican en primer lugar a las actividades de los científicos, y sólo de forma derivada a sus resultados. $\mathrm{Y}$ esas actividades humanas ocurren en el 'mundo dos', no en el 'mundo tres. Solamente un parti pris injustificado, que crea un abismo insalvable entre esos dos mundos, es lo que permite suponer que todo lo que en la actividad crítica no se 'traduce' directamente en componentes del tercer mundo es (a) irrelevante para explicar la cientificidad de la ciencia, (b) corresponde a factores 'irracionales' o 'no epistémicos' $y$, por consiguiente, (c) no tiene nada que ver con la explicación del crecimiento del conocimiento científico. Pero nada de eso se puede afirmar a priori. Si la crítica es tan fundamental como en el caso de Popper, se hace necesario estudiar el conjunto de sus condiciones de posibilidad tal cual se manifiestan en su 'lugar natural', las controversias, para poder decidir cuáles de entre ellas son pertinentes para dar cuenta de la 'racionalidad' de la ciencia."

TESIS B: La investigación rigurosa de las controversias es un medio indispensable para constituir una descripción adecuada de la historia y de la praxis de la ciencia. Y eso es as; porque las controversias son el 'contexto dialogico' natural en que se elaboran las teorias y se constituye progresivamente su sentido. Además, la investigación de las controversias permitira determinar empiricamente, por una parte, la naturaleza precisa de las 'crisis' y 'rupturas' que supuestamente introducen un elemento de irracionalidad en la evolución de la ciencia $y$, por otra, en qué 
consiste la 'continuidad' que supuestamente se requiere como trasfondo para el 'cambio' y la 'innovación' conceptuales.

En esta tesis se observa un denominador común con el descriptivismo: la importancia que atribuyo a la descripción cuidadosa del proceso histórico de evolución de la ciencia, donde las controversias tienen un rol decisivo. A diferencia de Kuhn y otros descriptivistas insisto, sin embargo, en el hecho de que no todo 'contexto' tiene el mismo peso. El contexto dialógico de la controversia es el contexto 'directo' de constitución del sentido de una teoría, y es en función de él como otros aspectos del contexto adquieren su pertinencia. Además, creo que la piedra de toque para comprender las supuestas diferencias entre ciencia normal y extraordinaria consiste, justamente, en saber si hay diferencias fundamentales entre las controversias que tienen lugar en una y otra. Ese es el camino por el que se podrá decir algo significativo sobre la existencia y naturaleza de fenomenos tales como la inconmensurabilidad, el cambio radical de normas, etc. ${ }^{10}$

En resumidas cuentas: la ciencia se manifiesta en su historia como una secuencia de controversias; éstas son, por lo tanto, no anomalías sino el 'estado natural' de la ciencia; en las controversias es donde se ejerce la actividad crítica, se constituye dialógicamente el sentido de las teorias, se producen los cambios e innovaciones, y se manifiesta la racionalidad o irracionalidad del ensayo científico; por todas esas razones, ignorarlas dentro de la filosofía e historia de la ciencia ha sido un error capital que hay que corregir.

\section{El fenómeno empírico del 'discurso polémico'}

Pero, ¿qué son, finalmente, las controversias cientificas? -se preguntará con razón el lector impaciente. En esta sección trataré de contestarle, situando la controversia propiamente dicha, y la controversia científica en particular, en el seno de la familia de fenómenos a que pertenece.

Esa familia es, evidentemente, la familia de los fenómenos discursivos dialógicos polémicos. No hay controversia propiamente dicha sin que por lo menos dos personas empleen el lenguaje, dirigiéndose la una a la otra, en una confrontación de opiniones, argumentos, teorías, etc. En ese sentido, la definición de la controversia que nos da Leibniz. (VOR, p. 18) en uno de sus fragmentos sobre el tema - "controversia est quaestio, circa quam opiniones contrariae habentur»- resulta claramente insuficiente (aunque quizás suficiente para Popper), pues es puramente lógico-semántica. Propongo también excluir de la extensión del término 'controversia' (aunque pueda pertenecer al campo de los discursos polémicos) lo que, siguiendo la terminología alemana, se podría denominar 'recepción crítica' 
-v.g., las diatribas de Popper contra Marx, Hegel, y Platón, en șu Open Society and its Enemies. Asimismo quedan excluidos los 'diálogos' pre-fabricados, como el de Leibniz con Locke en los Nouveaux Essais."1

La razón para excluir esos casos tiene que ver con mi insistencia en la controversia en cuanto actividad, y - más aún- actividad que comporta siempre un elemento de imprevisibilidad. En la controversia resulta esencial la posibilidad y el uso del derecho de contestación al oponente por parte de cada uno de los contendientes. Eso es así porque un oponente vivo, real y activo (es decir, ni muerto, ni imaginario, ni silencioso) es impredecible en sus reacciones. Aunque podamos anticipar aproximadamente la reacción de nuestro oponente, y hasta tratar de manipularlo para que reaccione de cierta manera, el juego de la controversia es esencialmente un 'juego estratégico', es decir, un juego en que nuestra capacidad de prevision de la jugada del adversario es limitada. ${ }^{12}$ Ese hecho es responsable en gran parte, en virtud de la capacidad que tiene la controversia para llamar la atención sobre confusiones y para engendrar aclaraciones, de forzar cambios conceptuales, metodológicos o teóricos y, finalmente, de imponer innovaciones.

Otra razón para no considerar como controversias la recepción crítica, el diálogo pre-fabricado y otros tipos semejantes de discurso polémico, es el hecho de que no sean realmente dialogicos. Es cierto que todo texto está, cuando menos implícitamente, dirigido a alguna audiencia y programado de antemano (cf. Clark 1992: xviii). Pero en el diálogo la audiencia está muy explícitamente definida, los roles hablante/oyente se alternan con gran frecuencia, y las 'exigencias conversacionales' (cf. Dascal 1977) cambian progresivamente con cada intervención de los participantes. Esas características del diálogo en general, que no sólo se aplican al debate oral sino también en buena parte a la controversia escrita (cf. Dascal 1989a), permiten comprender algunos de sus aspectos: el carácter variable o ad hoc de los argumentos empleados en ella (dependiendo del oponente, de la etapa de la controversia, etc.), el carácter dinámico y no estático de la definición de la problem situation en el curso de la controversia, los cambios temáticos relativamente inesperados que sufre, etc.

Concebida como fenómeno dialógico, la controversia consiste entonces, primariamente, en aquellos textos o intervenciones orales directamente dirigidos por cada contendiente al otro (o a los otros), privada o públicamente. Además de este 'texto primario', por lo general hay un amplio 'texto secundario' que, al menos parcialmente, pertenece a la controversia. Incluye, por ejemplo, obras de los contendientes en que se refleja - directa o indirectamente- la controversia, cartas a terceros en que se alude a la controversia, etc. Un círculo más amplio de textos pertinentes para la controversia constituye su 'co-texto', que incluye, por ejemplo, las obras de autores anteriores o contemporáneos que ambos contendientes citan o en 
las que se apoyan, etc. Finalmente, todo diálogo se inserta en un 'contexto' no discursivo, cuyos varios aspectos tienen siempre un papel más o menos importante en el contenido y desarrollo de las controversias. ${ }^{13}$

Todo lo dicho anteriormente se aplica a toda la familia de los diálogos polérnicos. Debemos ahora tratar de distinguir la posición especial de la controversia en esta macro-familia, que incluye, entre sus muchos miembros, las peleas verbales entre cónyuges, los debates políticos, las mesas redondas en los congresos científicos, las recensiones criticas de libros y sus réplicas, las disputationes medievales, etc. Se han propuesto, en forma mas o menos ad hoc, varias clasificaciones, que no tengo espacio para discutir aquí. ${ }^{14}$ Voy a ofrecer una taxonomía que se ha revelado útil en el curso de mi trabajo sobre el tema. ${ }^{15}$

Reservemos el término 'polémica' para designar el conjunto de los fenómenos discursivos dialógico-polémicos, cuyas características generales han sido descritas anteriormente. En este conjunto, propongo distinguir tres 'tipos ideales', miembros de la sub-familia a la cual pertenecen las controversias, que voy a denominar 'discusión', 'disputa', y 'controversia'.

Una discusión es una polémica cuyo objeto es un tema o problema bien circunscrito. Al desarrollarse, los contendientes tienden a reconocer que la raíz del problema es un error relativo a algún concepto o procedimiento importante en un campo bien definido (aunque divergen respecto a la naturaleza del error en cuestión y a quien lo comete). Las discusiones permiten soluciones, que consisten en corregir el error gracias a la aplicación de procedimientos aceptados en el campo (como prueba, cálculo, repetición de experimentos, etc.).

Una disputa es una polémica que también parece tener por objeto una divergencia bien definida. Pero los contendientes no aceptan en ningún momento que su definición esté basada en algún error. Más bien se revela como derivada de una diferencia de actitudes, sentimientos, o preferencias. No hay procedimientos mutuamente aceptados para decidir entre ellas, es decir, no tienen 'soluciones'. ${ }^{16} \mathrm{~A}$ lo sumo pueden ser disueltas. Pero, por lo general, las divergencias subyacentes a ellas tienden a incurrir de nuevo en disputas sobre otros tópicos específicos. Algunos contendientes ven en la posición de sus oponentes síntomas de una enfermedad frente a la cual la única actividad apropiada es terapéutica.

Una controversia es un tipo de polémica que ocupa una posición intermedia entre la discusión y la disputa. Puede empezar con un problema específico, pero rápidamente se expande a otros problemas y revela divergencias profundas. Estas involucran tanto actitudes y preferencias opuestas como desacuerdos sobre los métodos vigentes para solucionar los problemas. Por esa razón, no se percibe la oposición como una simple cuestión de errores, ni existen procedimientos aceptados para decidirlas, lo que causa el prolongamiento de las controversias y a veces su recurrencia. Sin 
embargo, no se reducen a meros conflictos irresolubles de preferencias. Los contendientes acumulan argumentos que creen incrementar el peso de sus posiciones, frente a las objeciones del adversario, tendiendo así, si no a decidir la cuestión, por lo menos a inclinar la 'balanza de la razón' a su favor, ${ }^{17}$ Las controversias no se 'solucionan' ni se 'disuelven', sino que se resuelven. La resolución puede consistir en el reconocimiento (por parte de los contendientes o de su comunidad de referencia) de que se ha acumulado suficiente peso en favor de una de las posiciones, o bien en la aparición de posiciones modificadas (gracias a la controversia) aceptables para los contendientes, o simplemente en la aclaración recíproca de la naturaleza de las divergencias en juego.

En las polémicas reales suelen manifestarse a la vez elementos de los tres tipos ideales, que los contendientes tienden a mezclar. Tampoco para el analista es fácil separarlos. Pero por lo general es posible identificar el tipo dominante. También en las polémicas entre científicos se mezclan los tres tipos y no es fácil separarlos. Una solución simplista consistiría en emplear la técnica popperiana de la demarcación. Al igual que distingue (en la ciencia) entre revoluciones 'ideológicas' y revoluciones propiamente 'científicas' (Popper 1981), la demarcación consistiría aquí en asimilar las polémicas científicas con las discusiones, considerando a las disputas como claramente 'ideológicas' (y por lo tanto sin interés alguno para la ciencia). ${ }^{18}$ En el polo opuesto, un kuhniano diria que las discusiones son tipicamente intra-paradigmáticas y caracterizan los periodos de ciencia normal, mientras en los períodos de ciencia extraordinaria lo que se da son esencialmente disputas. Ambas demarcaciones no dejan lugar para las coniroversias (que tienden a asimilarse con la discusión o la disputa) y, por lo tanto, no son capaces de reconocer sus características esenciales y su papel fundamental. Esa dificultad no es simplemente circunstancial, sino que resulta de ciertos presupuestos básicos, que se discutirán en la sección 5. Antes de eso, describiré con un poco más de detalle algunas de las características básicas de las controversias. ${ }^{19}$

\section{Algunas caracteristicas esenciales de las controversias}

I. La primera característica importante de las controversias es que no quedan confinadas a los problemas iniciales que las mótivan, sino que se amplían rápidamente, tanto en extensión como en profundidad.

En uno de los ciclos de la controversia entre Malthus y Ricardo, por ejemplo, el problema inicial es la cuestión de las com laws, que imponen restricciones a la importación del maíz eri el Reino Unido. Rápidamente, sin embargo, ese problema pasa a segundo plano, y el intercambio epistolar pasa a enfocar cuestiones tales como las relaciones entre ganancias e interés, entre los salarios y el precio real del trabajo, entre la demanda de 
alimentación y el consumo de productos de lujo, así como cuestiones metodológicas como la distinción entre leyes permanentes y tendencias temporales, la naturaleza del lenguaje científico, si las teorías tienen que ser monocausales o pluricausales, etc. ${ }^{20}$ Es importante señalar que todos esos temas son introducidos en la discusión sin indicadores de que se trate de digresiones (cf. Dascal y Katriel 1979), lo que muestra que el problem shift es percibido por los contendientes como directamente pertinente para el tema inicial. Es decir, la evolución temática de la controversia se rige, por lo menos parcialmente, por condiciones intrínsecas de relevancia semántica o pragmática.

En el curso de una controversia, los problemas iniciales son dejados a un lado por completo con mucha frecuencia, hasta tal punto que la controversia puede clausurarse con la adopción de una de las posiciones opuestas, sin que esa posición sea capaz de solucionar tales problemas. En la controversia sobre la separación de los continentes, uno de los problemas iniciales que la teoría de la primitiva unión de los continentes y su subsiguiente deriva separatoria (propuesta por Wegener en 1912) se propone resolver es el de las semejanzas observadas en las formas de vida existentes en continentes actualmente distantes. Las teorías alternativas, que niegan el movimiento de los continentes, dan cuenta de ese fenómeno por medio de hipotesis ad hoc (como la existencia de 'puentes intercontinentales' cuya desaparición posterior no saben explicar). Sesenta años después, al clausurarse la controversia a favor de la teoría de la deriva continental (aunque substancialmente modificada), la evidencia 'decisiva' que la fundamenta proviene de otro campo de investigación (el paleomagnetismo), y el problema paleobiogeográfico inicial, al que Wegener había atribuido una importancia decisiva, queda finalmente sin solución. ${ }^{21}$

II. En el curso de la expansión de la problemática, los contendientes cuestionan presupuestos básicos de sus adversarios, ya sean éstos fácticos, metodológicos o conceptuales. Así, en su esfuerzo por rechazar la teoría malthusiana del valor, Ricardo se limita a negar un hecho afirmado por Malthus: que la experiencia (repeated experience) demuestra que «the money price of labour never falls till many workmen have been for some time out of work» (Ricardo to Malthus, 21 July 1821; WC, IX: 25). El rechazo de este presunto (pues no existía en la época una información estadística adecuada) hecho ejemplifica, a su vez, la postura metodologica general de Ricardo, según la cual es más importante para una hipótesis el verse apoyada por general reasoning que el resultar conforme a los hechos (ibid.). Análogamente, en la referida controversia sobre la deriva continental, Simpson ataca a sus oponentes por emplear datos incorrectos basados en errores de identificación de los fósiles, por subestimar la capacidad de dispersión de varios organismos, por resumir incorrectamente datos pro- 
venientes de otras investigaciones, y por no considerar la posibilidad de evolución paralela o convergente - lo que ejemplifica cuestionamientos fácticos, metodológicos y conceptuales, respectivamente. Otro ejemplo viene dado por la expansión y profundización de la controversia entre Geoffroy de Saint-Hilaire y Cuvier sobre la existencia o no de un 'plano de organización' uniforme subyacente a la anatomía de todas las especies animales. Como muestra Gil (1985), ese problema aparentemente bien delimitado y 'técnico' lleva a una breve pero dramáticamente intensa controversia en la que "a whole series of fundamental epistemological decisions was at stake» (p. 358). Mientras Cuvier favorece la multiplicidad, la diversidad y la discontinuidad, exige una fidelidad estricta a los datos, el empleo de un lenguaje preciso, y el uso bien controlado de la analogía, Saint-Hilaire toma posiciones exactamente opuestas: defiende una unidad subyacente a la multiplicidad, critica el empirismo, no se preocupa del rigor de las definiciones, y emplea libremente la analogía.

Es notable la semejanza entre las oposiciones entre Cuvier y Saint-Hilaire y aquellas que hemos descubierto entre Malthus y Ricardo (cf. Cremaschi y Dascal 1996). Mientras el primero adoptaba una metodologia anti-deductivista, anti-apriorista, aspirando a una adherencia 'exacta' a la realidad, el scgundo prefería sacrificar esa adherencia a la simplicidad de leyes universales y 'rigurosas'. En términos de Granger (1959: 103), uno valoraba sobre todo el espíritu de la exactitud, y el otro, el espíritu del rigor. Ambos, sin embargo, profesaban fidelidad a un 'mismo' paradigma científico, inspirado por Newton - lo que muestra que aun dentro de un 'paradigma' hay margen para interpretaciones radicalmente diferentes (véase el próximo subepígrafe). La notable coincidencia entre las oposiciones metodológicas subyacentes a las dos controversias sugiere que, por detrás de sus opciones conscientes, los científicos se oponen también en virtud de casts of mind diferentes, es decir; de modos diferentes de concebir la finalidad misma de la actividad científica, diferencias éstas que afectan profundamente su ejercicio de esa actividad.

III. Una tercera característica importante de las controversias es su aspecto hermenéutico. La cuestión de la interpretación correcta de los datos, del lenguaje, de las teorias, de los métodos, y del status quaestionis, se plantea a cada momento. A cada paso los contendientes se acusan mutuamente de presentar incorrectamente las tesis del otro, de emplear un lenguaje ambiguo, de no contestar a las objeciones, y de no centrarse en el 'verdadero problema' que hay que resolver, ya sea en una fase determinada de la controversia, ya sea en general. Los ejemplos abundan en todos los tipos de controversia, y por ello me abstendré de ilustrar el fenómeno.

Una cuestión interesante es la razón o función que puedan tener esos (supuestos o reales) 'malentendidos' en la controversia. He formulado la 
hipótesis (cf. Dascal 1990a) de que tienen que ver con el hecho de que, al entrar en una controversia, los contendientes asumen el doble deber de defender sus teorias y criticar las de los adversarios. Ahora bien, una manera relativamente fácil (y corriente) de cumplir con esas obligaciones es invocar (en cuanto defensor) y emplear (en cuanto atacante) la 'distorsión': escapo a la crítica de mi oponente alegando que ésta no se aplica realmente a mi teoría, sino a la versión equivocada que ha dado de ella; ataco más eficazmente a una 'reconstrucción' (posiblemente simplificada) que propongo yo mismo de la teoría del oponente, que a esa teoría misma en toda su complejidad. La hipótesis en cuestión no es psicológica, pues no estoy acusando a los contendientes de mauvaise foi. Más bien emplean la estralegia del malentendido en razón de las obligaciones objetivas que asumen al entrar en una controversia.

IV. El carácter dinámico de la problemática, el cuestionamiento continuo de los presupuestos, y la 'libertad hermenéutica' que adoptan los contendientes llevan a la cuarta - quizás la más importante- característica de las controversias científicas: su 'abertura'. Lo que quiero decir con este término es lo siguiente: $a$ ) al empezar una controversia, no sabemos por dónde nos va a llevar su dinámica propia; $b$ ) difícilmente se confinan a una sola disciplina; $c$ ) revelan la existencia de divergencias profundas respecto al significado de los conceptos, métodos y hechos hasta entonces aceptados; $d$ ) no es posible anticipar la totalidad de las objeciones del oponente; e) preparan el terreno para las innovaciones radicales -incluso se podría decir que invitan al surgimiento de ideas, métodos, técnicas, e interpretaciones no convencionales.

V. Un aspecto especial de la abertura de las controversias, que conviene señalar como su quinta característica, atañe a la cuestión de su clausura, que ha sido objeto del volumen compilado por Engelhardt Jr. y Caplan (1987). En ese volumen, Beauchamp (1987 28-35) y McMullin (1987: 7782) proponen dos tipologías semejantes. ${ }^{22}$ Dejando a un lado la 'muerte natural' (Beauchamp) o el 'abandono' (McMullin), se pueden reconocer claramente en las dos tipologías los tipos de finalización que he señalado como característicos de las discusiones y las disputas. La 'resolución' (McMullin) y la 'clausura por argumento correcto' (Beauchamp) son ejemplos de lo que he llamado 'solución' (de una discusión), mientras que la 'clausura' (McMullin) y la 'clausura procedimental' (Beauchamp) son características de las disputas que no se pueden dar por cerradas sin la intervención de algún árbitro investido con la necesaria autoridad, aunque esa autoridad a lo sumo 'disuelva' la oposición a efectos prácticos, sin resolver efectivamente el conflicto de actitudes.

Curiosamente, lo que falta en ambas tipologías son los tipos de clausura 
intermedios, más abiertos que los algoritmos que solucionan las discusiones, pero no tan arbitrarios como los medios para disolver las disputas. La 'negociación' y el 'consenso' de Beauchamp podrian ser un ejemplos de esos medios intermedios, en la medida en que su poder de decisión es contingente (y por lo tanto provisional), depende de los contendientes mismos, y es reconocido como tal por ellos. Sin duda, esas formas de 'cerrar sin clausurar' corresponden a la abertura típica de las controversias. Sin embargo, subrayan demasiado el 'acuerdo' que debe regir la clausura, aun si es 'abierta'. Pero las controversias pueden terminarse también sin acuerdo. Lo interesante es que incluso en esos casos son percibidas por los participantes y analistas como 'productivas'. Aun cuando no permitan ni siquiera inclinar la balanza en favor de una de las posiciones, contribuyen en el plano cognitivo o epistémico de varias maneras: aclaración del problema, reconocimiento de las dificultades o divergencias conceptuales o metodológicas, reorientación del esfuerzo de la investigación, o simplemente 'comprensión'. En su conjunto esas contribuciones son decisivas para preparar el terreno para la innovación radical, que muchas veces cristaliza en una alternativa distinta de las posiciones mantenidas por los adversarios en la controversia. ${ }^{23}$

VI. La 'abertura' de las controversias no significa que sean anárquicas. Aunque no estén regidas por reglas implícita o explícitamente codificadas, como lo son las discusiones, no caen en el otro extremo - el anything goes. Aunque no se decidan por un 'tribunal de la Razón' (Kant), ni por un 'juez de las controversias' imparcial (como el idealizado alguna vez por Leibniz), ${ }^{24}$ no se zanjan por lo general a puñetazos o con invectivas. Aunque su evolución temática y el cambio de su problemática puedan verse influenciados por acontecimientos externos (descubrimientos en otras disciplinas, nuevas tecnologías, necesidades prácticas apremiantes), tiene que respetar también principios de pertinencia intrínsecos a su contenido. En suma, las controversias científicas manifiestan alguna forma de orden o sistematicidad, suficientemente débil para no despojarles de su abertura esencial, pero suficiente todavía para que su desarrollo no sea totalmente arbitrario. En este orden de cosas, se expresa - a mi modo de ver- una forma especial de racionalidad, que compete dilucidar a la teoría de las controversias.

\section{El impasse y las controversias}

Paso ahora a conectar el impasse descrito en la primera sección con lo que he dicho sobre las controversias en las demás secciones. Mi hipótesis es que tal impasse obedece a que las principales posiciones existentes en la filosofía e historia de la ciencia son incapaces de reconocer y explicar el papel de las controversias en la formación, evolución, y evaluación de las teorías científicas. O sea, voy a defender la siguiente tesis: 
TESIS C: Ni las formas conocidas de normativismo, ni las formas conocidas de descriptivismo permiten la existencia de controversias cientificas teniendo en cuenta el papel que se les ha otorgado y las características que se han descrito en las secciones 2-4.

Para completar mi argumento, sería necesario defender también la tesis siguiente:

TESIS $C^{\prime}$ : No se han propuesto hasta ahora alternativas al nomativismo y al descriptivismo capaces de dar cuenta del papel de las controversias.

Sin embargo, no voy a defender C'aquí, excepto en comentarios marginales sobre algunas de esas 'alternativas", porque (a) no tengo la pretensión de haber examinado toda la literatura reciente sobre el tema y (b) no me parece - por los ejemplos que conozco- que quienes han propuesto alternativas hayan reconocido la dificultad básica que identifico como causa del impasse, razón por la cual no se han preocupado por superarla.

Mi argumentación en apoyo de la tesis $C$ consistirá en mostrar cómo las posiciones descriptivistas y normativistas 'clásicas' excluyen la posibilidad de la existencia de controversias (en mi sentido), por no permitir la realización de una o varias de sus propiedades esenciales. De esa exclusión resulta una polarización que reduce el campo de las polémicas a dos únicos tipos - la discusión y la disputa- con sus respectivos modos de tratamiento' apropiado. Mostraré finalmente cn qué medida cabe encontrar en Kant una anticipación de esa situación. En la siguiente sección argumento que la solución del impasse requiere que demostremos la posibilidad de trascender esa polarización.

I. Las posiciones predominantemente descriptivistas subrayan, en sus diferentes versiones, la variedad y variabilidad de los factores que intervienen en las polémicas científicas. Aunque traten de distinguir entre los factores 'epistémicos' y 'no epistémicos' que actúan en esas polémicas, reconocen que esa misma distinción es contingente. Es decir, diferentes disciplinas o 'comunidades de expertos', fieles a diferentes 'paradigmas' o 'matrices disciplinarias', en diferentes momentos históricos, efectúan la distinción en cuestión de forma diferente. De ahí resulta que, para tener valor 'epistémico', la actividad crítica tiene que conformarse con la forma en que una determinada comunidad delimita ese valor. Eso significa que, necesariamente, sólo tendran valor 'epistémico' las controversias 'internas' al grupo. $O$ sea, el espacio de las controversias 'legítimas' es esencialmente predeterminado por un conjunto de normas contingentemente "válidas' para cada 'comunidad de debate'. Tratar de emprender un debate trans-comunitario es como tratar de jugar dos 'juegos de lenguaje' diferentes aplicando las mismas reglas. Las reglas que definen cada 'juego epistémico' no pue- 
den explicar semejante empresa; para explicarlo -cuando ocurre- hay que apelar a factores 'no epistémicos'. En otras palabras, la polémica trans-comunitaria, o bien es absurda y sólo produce equívocos, o bien ese valor - si es que tiene alguno-solo puede ser 'no epistémico', a menos que, contrariamente al presupuesto fundamental del descriptivismo, se adnita la existencia de normas epistémicas supra-comunitarias.

La lógica interna del descriptivismo nos obliga, por lo tanto, a concebir las controversias, o bien como caracterizadas por su comportamiento correcto', es decir, conformes a las normas intra-comunitarias que garantizan su valor 'epistémico', o bien como conflictos regidos exclusivamente por factores 'no epistémicos'. En el primer caso, se trata de lo que he llamado 'discusiones'; en el segundo, de 'disputas'. No queda espacio para las 'controversias' propiamente dichas, porque no queda espacio para la 'abertura' que permite la 'innovación radical' —aquella que, precisamente por basarse en una crítica 'profunda' que incluye la revisión de las demarcaciones contingentemente dadas entre lo 'epistémico' y lo 'no epistémico, no puede ser incluida en una u otra categoria.

II. Otra tendencia del descriptivismo, que le impide explicar otras características de la controversia, es su 'contextualismo'. En la medida en que tiende a explicar y no sólo a describir las normas vigentes en una comunidad científica, lo hace en términos de causas externas (sociales, políticas, históricas, psicológicas, etc.). Eso significa que, en última instancia, la verdadera explicación de cada uno de los aspectos de la actividad científica tiene que basarse en uno u otro tipo de causas privilegiadas. Se niega así cualquier 'autonomía' - aunque sea relativa - a fenómenos como la 'evolución temática' de una controversia. Estos tienen que resultar, en última instancia, de la influencia de acontemientos externos. La suposición de una 'lógica interna', de una 'pertinencia' semántica o pragmática, es espúrea - una mera ilusión. En sus formas extremas, esta tendencia lleva a la tesis de que toda 'reconstrucción racional' (que no sólo Lakatos, sino también Kuhn, consideran necesaria) de esos procesos, en términos de su presunta lógica interna, pertenece al orden de la 'racionalización' (Freud), 'ideología' (Marx), o 'camuflaje' de lo que realmente ocurre en todo proceso discursivo - la lucha por el poder (Foucault). Según esto, también las polémicas que han observado un 'comportamiento correcto' no son sino jugadas en una 'disputa', destinadas a defender un 'régimen de verdad' contra sus rivales.

El problema principal de ese contextualismo reside en la dificultad de establecer la determinación de contenidos y de las relaciones entre contenidos por sus presuntas causas. Se puede sugerir que las hemorroides de Marx determinaron su teoría de la alienación (Bartley III 1987: 430-431), pero es difícil demostrarlo, excepto por una vaga analogía entre los dos 
fenómenos. Asimismo, argumentos maquiavélicos genéricos del tipo cui bono sólo adquieren poder explicativo si la conexión entre los presuntos 'intereses' del agente y el acontecimiento que los favorece es establecida de modo independiente: que un reo tenga un 'motivo' para el crimen no supone sino una evidencia adicional para condenarlo. Pero, por lo general, el contextualismo se contenta con esos tipos de argumento, y difícilmente consigue establecer conexiones causales concretas. La relación entre contexto y contenido no es, a mi entender, de naturaleza unilateral, sino bilateral. El contexto contribuye a la determinación del contenido, pero éste contribuye, en no menor medida, a la determinación del contexto pertinente, es decir, nos permite afrontar selectivamente la infinitud de los factores contextuales. Esta interacción bilateral entre contexto y contenido es esencialmente abierta, y constituye una de las condiciones esenciales para conprender la recurrencia de las cuestiones interpretativas o hermenéuticas en las controversias.

III. Si el descriptivismo peca por suprimir o minimizar la autonomía de los procesos internos en la evolución de la ciencia, el normativismo peca por exagerarla. Sin embargo, el resultado - paradójicamente- es el mismo: una pre-determinación o cierre del espacio de la crítica 'legítima', que transforma en arbitraria, cognitivamente irrelevante o 'ideológica', toda crítica que no se conforme a las limitaciones de ese espacio.

Como ya he indicado, en su esfuerzo por demostrar la 'racionalidad' de las revoluciones científicas, Popper (1981) introduce una sharp distinction (p. 99) entre revoluciones 'científicas' e 'ideológicas'. Las primeras responden a un criterio lógico de progreso: la nueva teoría tiene que ser capaz de explicar todos los hechos explicados por las teorías anteriores que viene a remplazar. Por eso son racionales. Para las segundas, aunque frecuentemente asociadas con las primeras, no existe un criterio racional de progreso; son simplemente 'modas intelectuales' y resultan de procesos de aceptación social, independientes de los méritos racionales de las teorías en conflicto (p. 100). Según Popper, aunque frecuentemente se mezclen las dos, se puede (y debe) distinguir claramente entre los dos aspectos: la révolución copernicana, por ejemplo, fue una revolución cientifica porque remplazó, satisfaciendo el criterio lógico del progreso, las teorías anteriores; pero tuvo también un impacto ideológico, al poner en cuestión dogmas teológicos y modificar la posición del hombre en el universo.

Por este ejemplo, pareciera que lo 'ideológico' comprende para Popper solamente aspectos ético-políticos y 'metafísicos', generalmente aceptados como 'no epistémicos'. Pero no es realmente así. Al hablar de la revolución einsteiniana, incluye en sus aspectos ideológicos también posturas metodológicas ( the myth that Einstein had reached his result by an essential use of epistemological and especially operationalist methods", p. 105), in- 
terpretaciones de la nueva teoria ("the dominance of a subjectivist interpretation of quantum mechanics", p. 106) y de la extensión de los cambios conceptuales que introduce (la modificación radical de los conceptos de espacio y tiempo). ${ }^{25}$ Pero no sólo no es evidente que cuestiones como ésas sean 'no epistémicas', sino que son precisamente las que surgen continuamente en el curso de las controversias científicas - donde se confrontan metodologías, interpretaciones, y significados opuestos, ya sea entre sí, ya sea con respecto a los establecidos. Postular que esas cuestiones ideologicas' están desprovistas de valor cognitivo racional, porque no obedecen a una norma pre-determinada y estricta de racionalidad, es simplemente limitar a priori su importancia. Supone, además, afirmar - con los descriptivistas- que no hay sino dos tipos de polémicas posibles: discusiones o disputas.

El mismo Popper formula muy claramente esta consecuencia, al contrastar el carácter 'conservador' de las revoluciones 'cientificas' con el carácter 'abierto' de las revoluciones 'ideológicas'. Las primeras son necesariamente conservadoras, porque tienen que preservar el éxito de las teorías anteriores. Por esa razón, "a scientific revolution, however radical, cannot really break with tradition» (p. 106). Las segundas, por otra parte, no viéndose restringidas por ese tipo de exigencia, son las que pueden romper efectivamente con la tradición. O sea, en contraste con su conocida 'retórica de la abertura' en la ciencia, Popper restringe radicalmente de hecho su ámbito, al calificar de no científicas las formas de abertura que no respeten su criterio de cientificidad. ${ }^{26}$

IV. Para hacerle justicia a Popper, habría que analizar la versión 'evolutiva' de su epistemología, desarrollada por él $(1981,1987)$ y sus colaboradores (cf. Radnitzky y Bartley III, comps.; Bartley III 1987, Campbell 1987). Pues en esa versión se dan mecanismos que permitirían explicar algunas de las propiedades de las controversias. Por ejemplo, el problem shift se explicaría así: la adopción de una nueva teoría resuelve algunos problemas, pero crea otros porque, como en la aparición de una nueva especie, cambia el 'medio ambiente', alterando así las necesidades de adaptación o las 'presiones selectivas' de los demás organismos (cf. Popper 1981: 83 y passim). Asimismo, se podría explicar la 'preparación del terreno' para el surgimiento y eventual florecimiento de innovaciones por el hecho de que la presión de la crítica, en cuanto mecanismo de 'selección natural', elimina las teorías que han sido refutadas, abriendo asi paso a las nuevas.

Sin embargo, la 'epistemología evolutiva', como las otras versiones de una epistemología popperiana que se preocupa por combatir las concepciones anti-realistas, tiene por objetivo fundamental garantizar la objetividad de las teorías que sobreviven a la presión crítica, es decir, su veracidad $\mathrm{o}$, al menos, su verosimilitud con respecto al mundo real (el Mundo 1). $\mathrm{Y}$ 
eso lo cree poder hacer estableciendo tan sólo una conexión de representatividad 'directa' entre Mundo 1 y Mundo 3, en donde se minimiza la intervención de los factores del Mundo 2 -es la conocida noción popperiana de 'conocimiento sin sujetos cognoscentes', a la que ya aludimos. Cualquier intervención del Mundo 2 en el ejercicio de la crítica -que ha de tener lugar enteramente en el Mundo 3- acarrea un peligro para su objetividad, y por eso tiene que ser considerada como 'no científica'. Pero esa crítica, purgada de sus aspectos de actividad y que opera únicamente como filtro selectivo, pierde también todo su carácter dialógico. Finalmente, cabe plantear aquí el inevitable tu quoque? Mientras que en la teoría de la evolución el mecanismo de selección natural tiene el status de una conjetura empírica, y por lo tanto es refutable, se diría que en la epistemología popperiana no hay posibilidad de refutar el mecanismo de selección natural de las teorias que postula. Pero si es así, ¿no nos encontramos aqui con un empleo de la revolución darwiniana, que es tan 'ideológico' como los que el mismo Popper denuncia al hablar de la revolución einsteiniana?27

V. El 'demarcacionismo' de Popper pertenece a la familia de las estrategias que tratan de defender la racionalidad aislándola o purificándola de factores 'extraños' (cf. Dascal 1990b). Con eso se obtiene su autonomía y presunto valor normativo. Pero el precio que se paga, al separar de forma sharp lo puro de lo impuro, es crear un abismo entre ellos, que después es imposible de salvar. Pertenecen simplemente a dos 'mundos' distintos, inarmonizables. Esta estrategia popperiana es reforzada por lo que llamo la 'semántica ingenua' (posiblemente, deliberadamente ingenua), que es la contrapartida exacta del 'contextualismo'. Se trata de concebir los contenidos como enteramente autónomos e independientes de su substrato textual, co-textual y contextual. Los textos son 'transparentes' y revelan -como las Escrituras para Lutero- su significado sin necesidad de un proceso de interpretación que toma en cuenta co-texto y contexto. No hay problemas de 'traduccion' entre esquemas conceptuales distintos, y mucho menos 'inconmensurabilidad' entre ellos. ${ }^{28}$ La filosofía de la ciencia no sólo no necesita de una sofisticada filosofía del lenguaje, sino que debe alejarse de ella como del diablo, pues puede llevarla a herejías relativizantes. ${ }^{29}$ Todo eso excluye, evidentemente, cualquier papel cognitivamente importante para la controversia real, aquella en que el contexto dialógico es esencial para la determinación del contenido de las teorías, no menos que para su evolución.

VI. El 'falsacionismo sofisticado' de Lakatos, aunque aspira a ser 'dialécti$\mathrm{co}^{\prime}$ ', adolece también al final de in 'monologismo' fundamental, probable resultado del hecho de que comparte con Popper la creencia, no sólo en la prioridad del normativismo, sino también en la 'semántica ingenua'. Con- 
viene resaltar aquí este monologismo poco subrayado de la concepción de Lakatos, pues implica claramente la negación de la relevancia del diálogo real, y por lo tanto de la controversia, en su metodología de los programas de investigación.

Según Lakatos (1970), un programa de investigación (P.I.) consiste en un conjunto de 'reglas metodológicas' de dos tipos: la 'heurística negativa' y la 'heurística positiva' (p. 132). La primera se ocupa en proteger el hard core del programa, desviando las objeciones hacia hipótesis auxiliares (algunas especialmente inventadas para ese fin) o a otros componentes marginales del P.I. (p. 133). La segunda se ocupa en desarrollar el programa según su 'política de investigación' pre-establecida (p. 135), articulando uno tras otro los diferentes modelos o teorías que forman la serie constitutiva del programa. Esa doble heurística es la que explica por qué, a diferencia de lo que implica la teoría de Popper, no hay 'muerte instantánea' de un programa (ni siquiera de una teoría) en virtud de una 'refutación'. Al contrario, hay que proteger de la crítica 'destructiva' a los programas en sus fases iniciales, para que puedan desarrollarse (p. 179). La doble heurística actúa así como un mecanismo de 'aislamiento', que crea alrededor del programa un ambiente esterilizado, sin los agentes tóxicos (datos experimentales contrarios al programa, programas antagonistas, etc.) que lo matarian antes de que pudiera desarrollarse.

La política de favorecer la proliferación de P.I. es una política tolerante y simpática ('dejar florecer mil plantas'), y contra ella no hay por supuesto nada que objetar. Lo que sí me parece objetable es el 'preformismo' inherente a esta concepción y a las metáforas orgánicas y ecológicas de que se sirve ${ }^{30}$ Ese preformismo es, a mi entender, lo que impide a la teoría de Lakatos explicar la posibilidad y el rol de las controversias. Dicho preformismo se manifiesta en diferentes formas y niveles:

a) El elemento histórico-dinámico de un P.I. se manifiesta en la sucesión de teorías o modelos que lo 'realizan'. Pero la 'identidad' del P.I. —que consiste en su doble heurística- es esencialmente fija, y constituye un trasfondo de los cambios 'superficiales' en sus manifestaciones reales. Tal como las células de un cuerpo mueren y son remplazadas por otras, controladas por el código genético del organismo, también cada modelo sucesivo «is bound to be replaced during the further development of the programme» (p. 136). Por esa razón la 'refutación' de cualquiera de ellos, al igual que la muerte de cualquier célula en particular, es 'irrelevante'. La heurística positiva no sólo predice esas refutaciones de antemano, sino que también procura una estrategia para 'digerirlas' (otra metáfora biológica) sin perjudicar al organismo.

b) Lakatos atribuye a los creadores de nuevos P.I. capacidades planificadoras y predictivas extraordinarias. No sólo predicen las refutaciones, sino también las etapas de desarrollo de los modelos., 
c) Las 'refutaciones' experimentales - anticipadas o no- no son decisivas ni esenciales para el progreso del programa (el cambio de modelos). ${ }^{32}$

d) A consecuencia de eso, un teórico puede desarrollar tranquilamente su programa en solitario. Un «Bohr solitario» puede trabajar en su escritorio "far ahead of the experimenter: we have a period of relative autonomy of theoretical progress" (p. 152).

El resultado global de ese preformismo y aislacionismo es el monologismo, que impide la atribución de un rol real y efectivo a la controversia, sobre todo a su capacidad - esencialmente dialógica - de profundizar y expandir la crítica de forma inesperada. Aunque Lakatos hable de la importancia de los 'programas rivales', su teoría simplemente dice que 'surgen' (p. 154), sin explicar cómo, algo en lo que no difiere de Kuhn; tampoco explica cómo se entabla y desarrolla la controversia entre programas rivales. De hecho, para él la 'crítica' no proviene necesariamente de un programa rival, pues puede perfectamente ser interna, e incluso 'anticipada'. Si recordamos, finalmente, su inequívoca asignación del proceso de crecimiento de la ciencia al dominio autónomo del Mundo 3,33 habremos de darles la razón a quienes ya han señalado inquietantes similitudes entre la 'dialéctica' de Lakatos y la de Hegel.

VII. Como indican claramente los prefacios a la primera y a la segunda ediciones de la Crítica de la Razón Pura, Kant considera escandaloso el hecho de que la metafísica, al contrario de la física y de las matemáticas, haya sido a lo largo de su historia un campo de batalla en el que vienen a engarzarse debates sin fin. El objetivo principal de la Critica es poner têrmino a ese escándalo y hacer así de la metafísica una ciencia respetable. En la medida de lo posible, la metafísica tiene que imitar a la física y a las matemáticas, las cuales han sabido cómo extirpar de su seno las controversias, "por efecto de una revolución hecha en un solo momento" (CRP, I, p. 67). Para eso hay que comprender a fondo la fuente, la naturaleza y la función de las controversias metafísicas, lo que hace Kant en la «Antitética de la Razón Pura». Aunque su análisis no se aplique directamente a las controversias cientificas, refiriéndose a ellas sólo indirectamente, contribuye a aclarar la estructura 'trascendental' del impasse que hemos estado tratando de comprender y, por lo tanto, merece la pena recordarla.

Como siempre, la técnica de Kant consiste en investigar los presupuestos o 'condiciones de posibilidad' del fenómeno estudiado —en el caso que nos ocupa, de las controversias metafísicas. La "Antitética», por consiguiente, se abre con una distinción entre 'tética' y 'antitética':

Si llamamos tética a un conjunto de doctrinas dogmáticas, entendemos por antitética, no las afirmaciones dogmáticas del contrario, sino el conflicto entre dos conocimientos dogmáticos en apariencia (thesi cum antithesi), sin atribuir a uno de 
ellos un título más perfecto que al otro. No se ocupa, pues, la antitética de afirmaciones unilaterales, sino que considera los conocimientos universales de la razón sólo desde el punto de vista del conflicto entre ellos y las causas de ese conflicto [CRP, II, p. 67].

Es decir, la 'antitética' se eleva a un plano superior al de las controversias mismas. Su primer objetivo no es decidirse en favor de una de las tesis 'dogmáticas' opuestas, sino comprender la estructura de las controversias y sus causas profundas: "La antitética trascendental es una investigación acerca de la antinomia de la razón pura, sus causas y sus resultados" (ibid.). La definición de controversia o conflicto implícita en este paso hacia un meta-nivel es totalmente independiente de la existencia de episodios histórico-discursivos en que se manifieste. Los conflictos de los que trata la antitética son profundamente distintos de los conflictos 'sofísticos'. Ellos (a) no se refieren a cuestiones 'arbitrarias', sino «a un asunto que la razón humana necesariamente debe hallar en su camino» (ibid.); y (b) no presentan una «apariencia artificial, que desaparece en cuanto se la observa, sino una apariencia inevitable que aun cuando no nos engañe, nos ilusionas (p. 68). Al contrario de lo que ocurre con los conflictos comunes, que pueden ser resueltos con relativa facilidad, las 'proposiciones sofisticas' que caracterizan la antinomia de la razón pura no son tan fácilmente descartables como lo son las proposiciones sofísticas comunes, porque:

No esperan confirmación en la experiencia, ni tienen refutación, y cada una de ellas encierra on sí contradicción, y, además de esto, encuentran en la naturaleza de la razón las condiciones de su necesidad, y, por desgracia, la afirmación contraria se halla fundada en razones válidas [p. 67].

El paso al meta-nivel y la inevitabilidad del conflicto es lo que hace suponer a Kant que hay un conjunto bien determinado de controversias posibles, que sus causas son esencialmente las mismas y que, al comprenderlas, la razón puede, si no evitarlas, comprender cuando menos sus propios límites. Esta suposición es la que le permite definir la tarea de la dialéctica de la razón pura como reductible a la contestación satisfactoria de un pequeño número de preguntas:

1) ¿Cuáles son en realidad las proposiciones donde la razón pura se halla inevitablemente sometida a una antinomia?

2) ¿Cuáles son las causas de esta antinomia? ¿Dentro de este concepto, puede la razón encontrar el camino seguro hacia la verdad? ¿Cómo y de qué manera? [p. 67].

Para cumplir con esa tarea, Kant va a descartar del análisis de la controversias todos los factores meramente circunstanciales que intervie- 
nen en ellas (cómo se inician, cómo terminan, qué estrategias emplean los contendientes, qué causas defienden, etc.), así como todo interés por «decidirse en favor de uno o de otro» (p. 68). Se trata de adoptar la actitud de un "juez imparcial» -en realidad de un 'meta-juez'- cuyo interés no es decidir la contienda, sino "averiguar si [su] objeto puede ser algo más que una mera ilusión en pos de la cual corren ambos" (p. 68). Desde este punto de vista superior, no es la decisión del debate lo que interesa, sino el análisis de su estructura y causas profundas. A esta actitud, la denomina Kant el método escéptico, que distingue del escepticismo. Mientras este último aspira a derribar slos fundamentos de todo conocimiento, para no dejarle nada seguro ni cierton (p. 68), el método escéptico - como la duda cartesiana - aspira a la certeza. Frente a las controversias, actúa ese método como el legislador prudente frente a las peplejidades de los jueces que tratan de aplicar las leyes. Dicho legislador ve en estas perplejidades síntomas de dificultades inherentes a las leyes, que lo llevan a corregirlas para evitar futuras perplejidades. De la misma manera, los conflictos antinómicos de la razon actúan como síntomas que llaman la atención sobre la necesidad de determinar con más cautela los principios y límites de la razón pura, ${ }^{34}$

Ese carácter sintomático de los conflictos es tan inevitable como esencial para la teoría kantiana. Es inevitable, porque deriva de la existencia de dos tipos de unidad o síntesis, que son igualmente legítimos (en sus esferas respectivas) y que vienen a expresar nuestra aspiración a la unidad: la unidad del entendimiento y la de la razón. Es esencial, porque es la única 'piedra de toque' (Probstein) que nos lleva a descubrir la arquitectura de nuestro conocimiento y a determinar lo que le cabe de jure a cada uno de sus componentes - única forma de, si no evitar esos conflictos, comprender al menos su verdadera naturaleza.

Por ello necesita la teoría de la razón del 'método escéptico' - único medio para comprender y superar así el conflicto. Las demás ciencias no lo necesitan: "su empleo en la matemática sería absurdo", pues dispone de métodos de prueba capaces de solucionar cualquier conflicto; y la "filosofía experimental" dispone de la experiencia, donde se hallan "los últimos medios para decidir tarde o temprano la cuestión (p. 68). Disponer de medios para la resolución de las controversias es lo que ha hecho progresar continuamente a esas ciencias, mientras que la metafísica se ha quedado estancada en un perpetuo debate. Una forma de transformarla en ciencia y hacerla progresar sería tratar de darle, como a las matemáticas y a las ciencias experimentales, un medio de solucionar sus debates. Se podría decir que eso es lo que han pretendido hacer los filósofos dogmáticos en su búsqueda del 'método'. Pero eso significaría creer que es posible solucionar los debates metafísicos. Kant, sin embargo, no lo cree, tal como se ha visto. La forma kantiana de sacar a la metafísica de su escandaloso 
estado de perpetua controversia consiste, más bien, en reconocer la insolubilidad de tales controversias, y servirse de ese reconocimiento para sacar conclusiones seguras sobre la naturaleza del conocimiento metafísico y sus límites. La controversia, desde este punto de vista, tiene un valor propedéutico para la metafísica. Por otra parte, su 'solución' - como la de todo síntoma- requiere una intervención terapéutica. Dicha terapéutica es esencialmente 'preventiva'. Se trata de elaborar una 'disciplina de la razón pura en su uso polémico', que permita evitar las transgresiones que tendemos (inevitablemente) a cometer, transgresiones que consisten en emplear constitutivamente (es decir, determinando conteridos) una facultad que tiene tan sólo una función regulativa.

Kant, por lo tanto, nos ofrece una tipología 'trascendental' de las controversias que, como la tipología implícita en las epistemologías contemporáneas que hemos examinado, admite solamente dos posibilidades: o bien se trata de conflictos que se pueden solucionar, o bien de conflictos que no se pueden solucionar. Los primeros son aquellos para los que hay métodos de decisión rigurosos y aceptados que terminan las disputas y permiten el progreso. Los segundos, aunque inevitables, no son sino síntomas de transgresiones de ciertas nommas de la racionalidad. Tratar de resolverlos sería caer en la trampa. Lo que hay que hacer es simplemente evitar las transgresiones que los engendran.

En ambos casos, la controversia, para Kant, no tiene ni puede tener un rol constitutivo en el progreso del conocimiento. ${ }^{35}$ Como la 'presión selectiva' ejercida por la crítica popperiana, no crea contenidos, sino que, a lo sumo, permite diagnosticar y eliminar los 'errores', Esa limitación esencial de su papel es indispensable para evitar que recaigamos en el estado de barbarie donde los conflictos reflejan, o bien luchas de poder entre 'imperios despóticos', o bien 'una completa anarquía'. ${ }^{36}$ Sin embargo, el precio a pagar para 'civilizar la controversia' es castrarla en lo que atañe a su capacidad innovativa, y someterla a una ley suprema e incontestable.

\section{Desideratum}

Si las teorías vigentes no sólo no dan cuenta de las controversias científicas en el sentido que he caracterizado, sino que, al fin y al cabo, tratan de demostrar que no pueden existir, ${ }^{37}$ no basta reconocer su mera existencia para demostrar su posibilidad. Pues las teorías vigentes interpretan eso que 'existe' como ejemplificación de algo distinto a las controversias. Por esa razón se necesita, además de la crítica entablada en la sección anterior, demostrar positivamente la posibilidad de la controversia.

Si la razón fundamental de la incapacidad de las teorías epistemológicas vigentes para dar cuenta de las controversias, es la dicotomía reductiva con la que conceptualizan la totalidad de las polémicas (aquellas que son 
racionales, porque se pueden solucionar por medio de reglas más o menos estrictas, y aquellas que son esencialmente aporéticas, porque son anárquicas y caen fuera del doninio de la razón), lo que se tiene que demostrar es la posibilidad de una tercera alternativa; una alternativa que muestre que, entre la racionalidad 'dura' (puramente 'calculadora' o 'lógica') y la arbitrariedad, existe la posibilidad de una racionalidad soft, siendo así que las controversias pertenecerían a esta esfera. ${ }^{38}$ Más aún, es necesario desarrollar la teoria de esa forma de racionalidad, que ha sido enteramente obviada en el pasado. Considero la elaboración de una teoría de las controversias' un paso esencial en esa dirección.

Si la polarización reductiva del conjunto de las polémicas deriva de una oposición radical entre lo 'cerrado' (regido por normas rigurosas) y lo 'abierto' (donde se suspenden todas las normas), lo que hay que demostrar es la posibilidad de una interacción dinámica y dialéctica entre abertura y cierre, que conecte ( $y$ no desconecte) los aspectos de estabilidad relativa ('cierre') y de inestabilidad ('abertura') en la evolución de la ciencia.

En suma, lo que hay que hacer es, ni más ni menos, resistirse al dilema que ve en la admisión de la contingencia de las normas el primer paso de un slippery slope que lleva inevitablemente a la irracionalidad y, por lo tanto, ve en la defensa de su carácter necesario la única posibilidad de salvación. La posibilidad de la existencia de controversias científicas con las características analizadas aquí depende de la demostración de que tal dilema es falso.

Satisfacer ese desideratum constituye, por descontado, una tarea ingente. En la última sección, me limitaré a indicar que existen cuando menos un modelo y un instrumento, directamente relacionados con las controversias, que pueden contribuir a la elaboración de una concepción epistemológica capaz de satisfacerlo.

\section{Por qué pragmática}

El modelo e instrumento que propongo es la pragmática -..la teoría de los usos del lenguaje.

I. Su carácter de instrumento apropiado para el análisis de las controversias es evidente, en la medida en que éstas son, ante todo, fenómenos lingüísticos. Sin embargo, es sorprendente observar que raramente se han estudiado las controversias científicas desde el punto de vista pragmático. ${ }^{39}$ Ello se debe, según creo, a la extraordinaria reluctancia - pasada y actual- esgrimida a la hora de admitir el papel fundamental que desempeña el lenguaje en la ciencia y en el pensamiento, así como la naturaleza esencialmente pragmática de ese papel $4^{40}$ Esa reluctancia se ha manifestado, por ejemplo, en el rechazo, por parte de Descartes, Bacon y otros, a atri- 
buir al lenguaje algo más que un rol puramente externo en el pensamiento y en la constitución del conocimiento científico -un rol de simple transmisión o a lo sumo organización de un pensamiento formulado de forma totalmente independiente del lenguaje. La misma reluctancia se manifiesta en el deliberado silencio mantenido por Kant, en sus principales obras, respecto al lenguaje ( $c f$. Dascal y Senderowicz 1992). Creo que la razón de esa reluctancia ha consistido, sobre todo, en el temor de que, al admitir un rol más fundamental del lenguaje en el pensamiento y en la ciencia, se estaría contaminándolos ipso facto con el elemento de arbitrariedad o contingencia característico de las lenguas humanas. Ese temor persiste en nuestro siglo, cuando incluso los que reconocen la importancia del lenguaje tratan de remplazar las lenguas naturales por sistemas simbólicos formalizados, que son los únicos que se consideran apropiados para los fines de la ciencia, o bien conciben a las lenguas naturales como si fueran sistemas formales dotados de una semántica 'transparente'.

Recientemente se ha dado un cambio significativo en esta actitud, enfatizándose cada vez más la importancia de los aspectos pragmáticos del lenguaje para la ciencia. Quizás el inicio de esa tendencia se pueda localizar en el libro de Mary Hesse (1966), cuyo trabajo - continuado por los de muchos otros investigadores- reconoció el valor cognitivo, la irreductibilidad y la indispensabilidad del uso de la metáfora en ciencia.

Granger es otro filósofo que ha reconocido la importancia del análisis de los elementos no semánticos del lenguaje de la ciencia, desde su Essai d'une philosophie du style. Para él, uthe textual appearances of science are no mere epiphenomena of scientific knowledge; they pertain to its very substance» (Granger 1985: 349), de lo que concluye que el filósofo de la ciencia debe interesarse en "registering and interpreting actual [linguistic] usage from the combined standpoints of syntax, semantics, and pragmatics», y no simplemente en «eliciting the grammatical rules of a perfect -or almost perfect- ideal Begriffschrifts (p. 351). Granger distingue cuatro tipos de discurso científico, a los que asocia diferentes grados de 'pragmagticidad'. Los discursos que llama 'polémicos' son, segrín él, los que contienen mayor variedad de elementos pragmáticos, lo que ilustra con el ejemplo de la conocida carta de Pascal al padre Noel (29 de octubre de 1647) sobre el problema de la existencia del vacío. El análisis pragmático le permite a Granger identificar las intenciones subyacentes a la carta de Pascal, reveladas en su empleo de la ironía, en el pesimismo que expresa sobre el valor de las controversias, así como en otras diversas indicaciones. Según Granger, su intención básica no es la de convencer a Noel de los errores de sus argumentos contra el vacío, pues no tiene en gran estima las dotes intelectuales de Noel; lo que le importa es establecer - para una audiencia más amplia que el propio Noel- una distinción entre una metodología o práctica argumentativa inadecuada a la ciencia (la de Nocl) 
y los requisitos de una argumentación metodológicamente válida (la de Pascal).41

Tanto la identificación de las metáforas de fondo que estructuran un texto como la de las intenciones básicas que lo gobiernan son esenciales para comprender su 'dirección argumentativa', sus presupuestos conceptuales, sus premisas esenciales - sin lo que no es posible evaluar la eficacia comunicativa y tampoco la validez lógica de sus argumentos. Además de ese nivel 'macro', el análisis pragmático supone también un instrumento esencial para el nivel 'micro' - la comprensión y evaluación de cada pasaje del texto, especialmente en el caso de las controversias. Dentro de un contexto polémico, ningún acto de lenguaje puede ser interpretado tan sólo en base a su semántica y a su sintaxis. Por ejemplo, sólo a la luz de la 'exigencia conversacional' establecida por la intervención anterior del interlocutor, así como con la ayuda de otros indicadores pragmáticos, es posible saber si la respuesta de su oponente consiste en una 'aceptación', un 'rechazo' o una 'duda', pues un 'no' siempre puede significar, en ese contexto, un 'tal vez' o un 'si...'. La 'lógica' de la controversia —en la medida en que existe- sólo puede ser aplicada mediante un proceso continuo de interpretación pragmática.

Para que pueda cumplir con su función instrumental en el análisis de las controversias, la pragmática tiene que refinar su aparato teórico. En primer lugar, tiene que dar cuenta del carácter a la vez cooperativo y competitivo del discurso polémico, lo cual puede dar lugar a formas especiales de respetar y violar las normas de cooperatividad e inteligibilidad de la comunicación. También tiene que proporcionarnos, además, los medios para distinguir empíricamente entre las diferentes formas de discurso polémico que hemos distinguido más arriba desde un punto de vista teórico. No creo que le resulte difícil a la investigación pragmática satisfacer estos $y$ otros requisitos.

II. Paso ahora a describir los aspectos de la pragmática que, a mi entender, permiten ver en ella un modelo de teoría capaz de satisfacer al desideratum formulado en la sección anterior.

\section{a) La relación semántica-pragmática}

La pragmática no remplaza a la semántica, sino que co-existe con ella. La interpretación pragmática de una expresión metafórica, por ejemplo, no puede prescindir de la existencia de su sentido 'literal' (cf. Dascal 1986). La semántica da cuenta de la codificación de los significados en un sistema de reglas. La pragmática permite servirse de ese sistema de una forma flexible, violando ocasionalmente sus reglas, sin sacrificar con ello la inteligibilidad. Esa relación simbiótica entre pragmática y semántica representa, a mi modo de ver, un excelente modelo para la posibilidad de sistemas 
(en este caso el lenguaje) en que se combinan 'cierre' y 'abertura', sin entrar a prejuzgar la eficacia del sistema. En particular, permite explicar: I) la posibilidad del cambio o evolución conceptual -incluso radical- sin que se de 'inconmensurabilidad'; II) las dificultades de la 'traducción' (menospreciadas por Popper y subrayadas por Kuhn), al tiempo que su posibilidad; III) el hecho de que puedan existir 'esquemas conceptuales' semánticamente 'cerrados', sin que eso impida la 'comunicación' (gracias a 'aberturas' pragmáticas) entre ellos. ${ }^{42}$

\section{b) La naturaleza de las reglas pragmáticas}

La pragmática está regida por normas que garantizan la inteligibilidad de los actos comunicativos. Pero esas normas, al contrario que las reglas semánticas, no son de naturaleza algorítmica, sino más bien heurística. Tienen el carácter de presunciones, es decir, sus conclusiones son aceptadas a condición de que no haya razones más fuertes para abandonarlas (cf. Dascal 1983). Se pueden formalizar por medio de lógicas 'no-monotónicas' o gradualistas (cf. Peña 1991). Esta característica de sus normas hace de la pragmática un buen modelo (y quizás también un instrumento de explicación) de la normatividad 'no rígida' - de la razón soft- que, dentro del ámbito de las controversias, permite justificar el no abandono de una posición frente a su aparente 'refutación' por parte del oponente: lo importante no es el mero valor lógico de la supuesta refutación, sino su 'peso' relativo frente a la presunción que favorece esa posición. Esto explica, a su vez, la feroz lucha en que se enzarzan los contendientes de una controversia para tener las presunciones (v.g., el onus probandi) a su favor.

\section{c) Razones como causas}

La interpretación pragmática ocupa, ontológicamente, un nicho muy especial. $^{43}$ Se trata de una forma de explicación causal, pues consiste en atribuir a un hablante, en base a su comportamiento lingüístico y a informaciones contextuales, una intención comunicativa que actúa como causa de ese comportamiento. Pero, tanto respecto a la forma en que un estado mental puede actuar como causa, como respecto a la inferencia que permite su atribución a un agente, difiere de la causalidad física común porque depende, esencialmente, del hecho de que la intención comunicativa del hablante y su comportamiento lingǘstico posean un 'contenido', cuyo reconocimiento por parte del oyente es indispensable para el éxito de la comunicación. Por reposar sobre ese tipo especial de causalidad, que se ejerce al nivel de los estados mentales conscientes de los interlocutores, el comportamiento comunicativo no se deja reducir a la explicación en términos de causas 'profundas', sobre las cuales el sujeto consciente no tiene control (cf. Dascal 1992c). Ofrece así el modelo de un proceso que escapa al tipo de determinismo causal al que tiende el descriptivismo 'contextua- 
lista', al mismo tiempo que sugiere un modelo para la armonización no reduccionista del Mundo 2 con los Mundos 1 y 3.

\section{d) Contingencia no arbitraria}

Las normas pragmáticas poseen una racionalidad instrumental, pues pueden ser vistas como corolarios de la concepción de la comunicación entendida como un proceso cooperativo. Hablamos coherente y claramente, decimos cosas relevantes, etc., porque deseamos que nos entiendan (y de esa forma tales normas vengan, posiblemente, a cooperar en la consecución de nuestras otras metas). En ese sentido, no son arbitrarias. Pero sí son contingentes, porque la idea misma de cooperación puede ser interpretada $(y$ de hecho lo es) de forma muy distinta en diferentes culturas y períodos históricos. Lo son, también, porque la idea misma de 'instrumentalidad' es interpretable de forma diferente en diferentes contextos. $O$ sea, que tenemos aquí un ejemplo de la posibilidad de un sistema normativo no arbitrario, contingente y variable, cuya no arbitrariedad, sin embargo, no necesita ser garantizada por una Razón universal inmune al cambio y a la crítica ${ }^{44}$

\section{NOTAS}

1. Mi presentación de la situación de la filosofía de la ciencia es obviamente esquemática. Sé que se han hecho muchos esfuerzos para salir del impasse que describo, y también entiendo que algunas de esas contribuciones tienen gran valor. No las menciono para simplificar la exposición de lo que me parecen ser las coordinadas básicas de la problem situation. Además de aclarar la problemática, eso me permite mostrar la especificidad de mis propuestas para su solución.

2. Lakatos empieza este texto con la siguiente paráfrasis de un famoso dictum de Kant: "Philosophy of science without history of science is empty; history of science without philosophy of science is blind . Como senala Hacking (1981: 138n), el dictum kantiano no habla de ceguera, sino de vision 'ciclópea': "Mere polyhistory is a cyclopean endition that lacks one eye, the eye of philosophy». La distorsion introducida por Lakatos en esta cita me parece muy significativa, pues, como trataré de mostrar más adelante, el gran problema en su propia manera de combinar descriptivismo con normativismo consiste en su carácter 'ciclópeo' o 'monológico', resultante a mi entender de la excesiva subordinación del primero al segundo.

3. "[...] the -rationally reconstructed-growth of science takes place essentially in the world of ideas, in Plato's and Popper's "thitd world", in the world of articulated knowledge which is independent of knowing subjectsw (Lakatos 1970: 179-180).

4. «[S]cientists behave in the following ways; those modes of behavior have [...] the following essential functions; in the absence of an altemate mode that would serve similar functions, scientists should behave essentially as they do if their concern is to improve scientific knowledgen (Kuhn 1970: 237).

5. Esa es otra forma en que, significativamente, expresa Kuhn (ibid.) la premisa (d). La normatividad 'đébil' de la propuesta de Stich (1994), a la hora de implementar el programa bautizado por Quine como 'naturalización de la epistemologia', experimenta dificultades semejantes a las señaladas en el texto, y otras más que discuto en Dascal (1995b).

6. Todo depende, en este angumento, del nivel de generalización de las descripciones 'maneras de actuar' y 'funciones esenciales'. Si son suficientemente generales (pero no vacias) 
como para aplicarse a diferentes paradigmas, engendran una normatividad más fuerte. Pero en ese caso, ponen en peligro la tesis de la 'inconmensurabilidad' entre paradigmas.

7. Y ese 'positivismo', evidentemente, es víctima fácil de un argumento del tipo tu quoque, el cual señalaria que las descripciones y análisis causales de que se sirve, al aplicarse a diferentes paradigmas, comunidades, y periodos históricos, tienen que obedecer a normas de veracidad trans-paradigmáticas.

8. Este párrafo me sabe demasiado 'metafísico' y abstracto. Sin embargo, el enzpleo de los términos kantianos se justificara más adelante.

9. Para otras diferencias con la posición de Popper y sus discípulos, remito a la sección 5.

10. Para otras diferencias, véase la sección 5 .

11. Se ha dado una verdadera controversia entre Leibniz y Locke, bajo la forma de correspondencia, a través de 'mediadores' como Lady Masham, por ejemplo.

12. Por esa razón, no se puede por lo general prever lodas las objeciones posibles a una tesis que se defiende (a menos que sea una tautologia), lo que bloquea la posibilidad de servirse de un 'atajo' que consistiría en demostrar en forma absoluta la tesis, haciendola así inmune a cualquier objeción futura. Leibniz aplicó ese argumento contra Bayle en su debate sobre los misterios de la fe (véase Dascal 1975).

13. Sobre las relaciones entre texto, co-texto y contexto, vease Dascal y Weizman (1987). Sobre las nociones de texto 'primario', 'secundario' y 'co-texto', véase Dascal (1990a). (1994).

14. Véase, por ejemplo, Granger (1985), Gil (1985), y especialmente Bohler y Katsakoulis

15. La he presentado por primera vez en el marco del grupo de investigación wLeibniz. the Polemicists, en el Institute of Advanced Studies (Jerusalen), en diciembre de 1994.

16. Excepto el recurso a alguna autoridad institucional, como un tribunal. Pero en esos casos, el conflicto de opiniones o actitudes no se decide, sino simplemente se reprime, pues, como bien dice Leibniz, nadie tiene el poder (potentia) de imponer al otro el olvido o la atención. condiciones indispensables para que tenga el poder de hacerle cambiar de opinión (VOR, p. 19).

17. Sobre el empleo de esa metáfora fundamental, véase Dascal (en imprenta $a$ ).

18. A diferencia de Frankel (1987), quien distingue entre controversias científicas 'puras' y controversias cientificas que tienen implicaciones políticas, éticas y prácticas, Popper considera 'ideológicas' también las 'revoluciones' en que predominan o intervienen consideraciones metodológicas o filosóficas. Véase más adelante, sección 5.

19. Como yo, también McMullin (1987: 88) afirma que hay que considerar la controversia cicntifica en su carficter de actividad, " ca complex human action in which social, political, and psychological factors play an important part». Pero, a diferencia de lo que propongo aquí. omite el hecho de que se trata primariamente de una actividad dialógica. Además, se apresura a agregar en la misma oración un significativo 'pero': abut in which epistemic factors are most likely to be determinative». Con eso se mantiene fiel esencialmente a la tendencia normativista, imponiendo a priori una distinción categorial (que le parece obvia) entre factores "epistémi$\cos ^{\prime}$ y 'no epistémicos'. Mencionando al Kuhn de The Essential Tension, para quien las ciencias 'maduras' se rigen por 'valores epistérnicos' como capacidad predictiva, coherencia y fecundidad, McMullin (p. 83) insiste en que estas nomas, aunque varien de científico a cientifico y de comunidad a comtnidad, "are not just contingent social conventions", porque ethey have been found to serve the basic end of science, which is problem solving». Evidentemente, esta definición (normativa) de la ciencia consiste simplenente en optar por la 'ciencia normal' como la verdadera expresión de la actividad científica, con lo que queda excluida la posibilidad de dar cuenta --en términos epistémicamente respetables- de las controversias en los periodos de 'ciencia extraordinaria', tal como las describe el Kuhn de The Structure of Scientific Revolutions. No es de sorprender que en la tipología de las formas de clausura de las controversias propuesta por McMullin (que discuto más adelante), nos encontremos únicamente con la dicotomia discusion/disputa, sin dejar lugar a lo que llamo 'controversia'.

20. Para un estudio detallado de esa controversia, véase Cremaschi y Dascal (1996 y en preparación) y Dascal y Cremaschi (en preparación). 
21. Por lo menos según el paleobiologista George Gaylord Simpson, que a lo largo de la controversia se habia opuesto a los partidarios de la deriva. Simpson escribe en 1971: «I now believe that continental drift did occur [...] but direct fossi] evidence is still curiously scanty or equivocal. The Cenozoic evidence indicates that drift had little or no zoogeographic effect in that era as regards most of the continents, including all for which the evidence is considerable or reasonably adequate [...] Now everything has to relate to plate tectonics [...] but it is rather amusing that currently there are four completely different plate tectonic 'explanations' of the early distribution of marsupials, none of them based on a reasonable balance of evidences (citado en Frankel 1987: 231-232).

22. Como referencia, reproduzco aquí los resúmenes de esas tipologías dados por los compiladores (Engelhardt Jr, y Caplan 1987: 5-6). McMullin: «1. Resolution. A controversy is resolved when an agreement is reached on the merits of the case in terms of what the participants take to be standard epistemic factors. 2. Closure. A controversy reaches closure when it is terminated on the basis of nonepistemic factors, such as the authority of the state, the pride, ambition, or laziness of a controversialist; or the withdrawal of publication facilities. 3. Abondonment. Controversies may terminate through participants losing interest $*$. Beauchamp: $* 1$. Sound angument closure: occurs if, and only if, a correct position has been reached [...] thereby rendering opposition views incorrect. 2. Consensus closure: occurs if, and only if, a consensus has been reached [...] through a means other than sound argurnent closure or some form of procedure or negotiation, that some position is best and that opposition views are incorrect. 3 . Procedural closzure: occurs if, and only if, a controversy is terminated by formal, procedurally govemed efforts to end the sustained discussion [...] 4. Natural deaih closure: occurs if, and only if, a controversy has come to an end through a gradual natural death, as by fading away because of waning interest, 5 . Negotiation clostere; occurs if, and only if, a controversy is settled through an intentionally arranged and morally unobjectionable resolution acceptable to the principals in the controversy".

23. En el caso de la controversia sobre la deriva continental, la teoria de las placas tectónicas (debida a Hess), que fue finalmente aceptada por los todos los contendientes, difiere significativamente de la teoria de la deriva, aunque comparta con ella la tesis del movimiento continental. La controversia preparo el terreno para la teoría de las placas tectónicas, no sólo por atraer la atención sobre la posibilidad del movimiento continental, sino también por la atssencia de cualçuier hipótesis razonable sobre el mecanismo responsable por ese movimiento. Como señala Thagand (1992: 161), la posibilidad de concebir ese mecanismo requirió un 'cambio conceptual' importante; el abandono del presupuesto (compartido por todas las teorías anteriores) de la uniformidad básica de la costa terrestre, y la admisión de una diferencia básica entre el material de los continentes y el del suelo maritimo.

24. En las raras ocasiones en que se constituyen 'tribunales cientificos' para decidir controversias científicas, no hay ninguna garantia de que la decisión del tribunal ponga fin a la controversia, como lo muestra la continuaciôn de la controversia sobre la generación espontánea, controversia que se mantuvo durante muchos años después de la decisión adoptada por la academia (1862), la cual se decantó a favor de Pasteur en su confrontación con Pouchet (cf. McMullin 1987: 89; Mendelsohn 1987: 105-113).

25. En palabras de Minkovski: "The views of space and time I wish to lay before you [...] are radical. Henceforth space by itself, and time by itself, are doomed to fade away into mere shadows, and only a kind of union of the two will preserve an independent reality. Despuess de citar a Minkovski. Popper agrega: "This is an intellectually thrilling statement. But it is clearly not science: it is ideology. It became part of the ideology of the Einsteinian revolutions (Popper 1981: 104).

26. Una restricción paralela a la abertura se encuentra, dentro del plano político, en su 'principio de la tolerancia limitada'. Sobre eso véase Dascal (1979 y 1989b).

27. La 'epistemología evolutiva' pasa sutilmente de un empleo literal a un empleo metafórico de la tcoria de la evolución, que puede ser reponsable de esta 'ideologización'. $\Lambda$ lo largo de la historia del pensamiento, la noción biológica de evolucion (concebida de diferentes for- 
mas por diferentes teorias) ha sido una metáfora formativa muy importante en filosofía. Merece un estudio similar al de mis otros estudios sobre metáforas básicas en filosofia (cf. Dascal en imprenta $a$ y $b$ ).

28. Contru lo que llama athe myth of the framework", que atribuye a Kuhn, dice Popper (1970; 56): "I do admit that at any moment we are prisoners caught in the framework of our theories; our expectations; our past experiences; our language. But we are prisoners in a Pickwickian sense: if we try, we can break out of our framework at any time. [...] critical discussion and a comparison of the various frameworks is always possible. It is just a [...] dangerous dogma that the different frameworks are like mutually untranslatable languages [...] even totally different languages are not untranslatable [...]».

29. Kuhn (1970: 268), por el contrario, subraya la dificultad (no la imposibilidad) de la traduccion ("Why is translation, whether between theories or languages, so difficult? $n$ ) y afirma la importancia de la filosofia del lenguaje (p. 235): «[...] philosophers of science will need to follow other contemporary philosophers in examining, to a previously unprecedented depth, the manner in which language fits the world, asking how terms attach to nature, how those attachments are learned, and how they are transmitted from one generation to another by the nembers of a language community».

30. Por ejemplo: «[...] a research programme can challenge a considerable bulk of accepted scientific knowledge: it is planted, as it were, in an inimical environment [subrayado mio] which, step by step, it can override and transform" (Lakatos 1970: 140). Evidentemente, la condición para que pueda superar ese ambiente hostil es que pueda gozar de un ambiente protegido, por lo menos al inicio.

31. All this was planned right at the start" (p. 146); aunque "Not all developments in [Bohr's] programme were foreseen and planned when the positive heuristics was first sketcheds (p. 153).

32. "In most cases we need no refutations to tell us that the theory is in urgent need of replacement: the positive heuristic of the programme drives us forward anyways (p. 151).

33. "[....] the - rationally reconstructed-growth of science takes place essentially in the world of ideas, in Plato's and Popper's "third world", in the world of articulated knowledge which is independent of knowing subjects» (pp. 179-180).

34. La comparación jurídica reaparece más adelante, en forma más detallada, en la «Disciplina de la razón pura con relación a su uso polémicom. Sobre proposiciones para adoptar un 'modelo jurídico' para la epistemología, vease Romano (1989) y Dascal (1990c).

35. Fernando Gil (1980), en un brillante capítulo sobre "Kant y la controversia", trata de reinterpretar los textos kantianos que hemos examinado ofreciendo la hipótesis, "meno kantiana, che le controversie siano costitutive e non un semplice preliminare dellesercizio del pensieros (p. 154). Aunque estoy plenamente de acuerdo con esta hipótesis -que es precisamente la que defiendo en el presente artículo- y también con su formulación leibniziana' ( aLa controversia $\hat{e}$ un aspetto di una razionalità intrinsecamente complessa, ne finita ne infinita, ma "confusa", more leibnizionon, p. 164), no entiendo el tour de force con el que Gil cree poder conciliarla con el texto de Kant.

36. En el prefacio a la primera edición, Kant describe ese escándalo con una metáfora extraondinariamente potente. La metafisica, nos dice, ha oscilado entre dos polos: el «imperio despóticon de los "dogmáticos" y la "completa anarquía" de los esscépticos". Los primeros dieron lugar a los segundos, porque usus leyes traian consigo rastros de antigua barbarien. mientras que los segundos permitieron el retorno de los primeros a causa de los primitivos métodos de ademolición" de las fortalezas dogmáticas que empleaban. Para superar esa oscilación escandalosa, Kant tratará, por una parte, de perfeccionar el 'método de demolición' y, por otra, de construir fortalezas basadas en 'leyes civilizadas' (es decir, 'principios regulativos'), inmunes a cualquier demolicion.

37. Yo incluiria el argumento de Davidson (1974) contra la existencia de esquemas conceptuales' distintos -y por ende contra la noción misma de 'esquema conceptual'-, en la lista de los argumentos que supuestamente demuestran la impasibilidad de controversias en que se 
oponen posiciones radicalmente diferentes, y que por eso permiten innovaciones radicales. Désafortunadamente, no dispongo aquí del espacio necesario para desarrollar esta interpretación de Davidson.

38. La distinción propuesta aquí es semejante, mas no idéntica, a la propuesta por Granger (1985: 350) entre lógica' y 'razón': "[...] the discourse of scientists allows one to perceive and explicitate two avenues to justification and proof. Roughly speaking, one might call the one "logic" and the other "reason". The first consists in calculating, insofar as abstract concepts and rules of deduction are strictly defined; the second consists in strategic choices, processes of orientation, and evaluation. [...] If we are to track the non--logical, though rational ways the discoverer has followed, then we must closely study his languages.

39. No hay que confundir un tratamiento pragmático con un tratamiento retórico. Este último se ha hecho popular en numerosos estudios sobre la 'retorica de la ciencia' (cf. Gross 1990 y 1993; Pera 1991) y ha generado una intensa polérnica, por ejemplo en economí (cf. McCloskey 1994a y 1994b; Mayer 1994; Maloney 1994). La diferencia esencial entre pragmática y retórica estriba, a mi entender, en que la última se interesa esencialmente por la producción de un determinado efecto en una audiencia - la adopción de una cierta opinión. Los medios para producirlo - lingüísticos u otros- se eligen exclusivamente en función de su eficacia causat. Desde ese punto de vista, la propaganda subliminal, la hipnosis, y el uso del lenguaje según normas de veracidad, potencial informativo, pertinencia y claridad (o sea, obedeciendo a las máximas de Grice) son alternativas igualmente legítimas. La pragmática, por otra parte, se interesa por los procesos propiamente comunicativas, es decir aquellos en que interviene necesariamente la capacidad de hablantes y oyenles para transmitir y reconocer intenciones comunicativas. En la medida en que esos procesos son de naturaleza esencialmente inferencial, involucran un tipo de causalidad muy especifico - aquella que nos lleva a aceptar una opinión o adoptar una interpretación de un enunciado en virtud de las 'razones' que aducimos para ello. La pragmática, en mi concepción, supone esencialmente el estudio de ese tipo muy específico de causalidad o de racionalidad. Véase más adelante, sección $7(c)$.

40. Para una panorámica histórica de la problemática de las relaciones lenguaje, ciencia, y pensamiento, véase Dascal (1994 y 1995). Para la importancia de la perspectiva pragnática en comprender esas relaciones, véase Dascal (1992).

41. El análisis pragmático en términos de intenciones que propone aquí Granger entra en conflicto, a mi modo de ver, con su conceptualización de la pragmática, que - como la de Apel y Habermas - tiende a la trascendentalización. Granger $(1979,1985)$ se sirve de la distinción kantiana entre principios "constitutivos" y aregulativos". Además distingue entre condiciones kempíricas" y «trascendentales», Para el las condiciones constitutivas empíricas del uso del lenguaje son el objeto de la psicología, sociología, etc., y no le interesan. Las condiciones constitutivas trascendentales, por otra parte, son ualgebraicas" y se resumen a la sintaxis y la semántica. Lo que queda para la pragmática, por lo tanto, son condiciones no constitutivas, sino regulativas, y no empíricas, sino trascendentales. De entre ellas aísla dos - las conditionts de visée (lo ilocutorio) y las conditions danchrage, que son responsables de la inserción de la experiencia personal en el uso del lenguaje. Pero, si lo psicológico ha sido descartado de la pragmática, ¿cuál es entonces el esujeto" o aindividuo" cuyas experiencias sirven para anclar la enunciación?

42. Davidson no admite que se pueda realmente hablar de 'normas' pragmáticas. Para él, lo que caracteriza la interpretación 'pragmática' es su carácter absolutamente 'abierto', no-convencional (cf. Davidson 1978 y 1985). Searle, por otra parte, toma por modelo de las normas pragmátícas las reglas constitutivas estrictas que emplea en su teoría de los actos de habla. Por esa razón, llega a la conclusión de que no se puede hallar una estructura pragmática en la conversación -conclusión que critico en Dascal (1992b).

43. Véase sobre esto la nota 39.

44. Una versión embrionaria de este trabajo fue presentada por primera vez en el Instituto de Filosofia del Consejo Superior de Investigaciones Cientificas (Madrid), en 1992. Luego, las ideas aqui expuestas fueron objeto de un seminario semestral de postgrado en el departa- 
mento de filosotia de la Universidad de Tel Aviv, Sirvieron después de base para elaborar el proyecto de investigación sobre la pragmatica de las controversias, que fue aceptado por el Institute for Advanced Studies de la Universidad Hebrea de Jerusalén, bajo la condición de que se concentrara en Leibniz. Eso dio origen al grupo internacional de investigación «Leibniz the Polemicist», que concluye en septiembre de 1995 su labor de un año, en el marco del Institute. Quiero agradecerles a todos los que tuvieron la paciencia de escucharme las ocasiones mencionadas sus críticas, comentarios, y estimulantes controversias. No me atrevo a nombrarlos por temor a cometer injusticias. A quien sí quiero nombrar es a Varda Dascal, que en el presente caso ha contribuido para con este trabajo mucho más alla de su habitual apoyo logistico y moral.

\section{BIBLIOGRAFIA}

BARTLEY III, W.W. (1987): aAlienation alienated: The economics of knowledge versus the psychology and sociology of knowledge», en Radnitzky y Bartley III (comps.), pp. 423-451.

Beauchame, Tom L. (1987): «Ethical theory and the problem of closure, en Engelhandt Jr. y Caplan (comps.), pp. 27-48.

BOHL.ER, D., y G. KaTSAKOulIS (1994): "Diskussion», en G. Ueding (comp.), Historisches Worterbuch der Rhetorik, vol. 2, Tubinga, Max Niemeyer, pp. 819-831.

CAMPBEL, Donald T. (1987): "Blind variation and selective retention in creative thought as in other knowledge processes», en Radnitzy y Bartley III (comps.), pp. 91-114.

CLARK, Herbert H. (1992): Arenas of Language Use, Chicago, The University of Chicago Press.

COHEN, Avner, y Marcelo Dascas (comps.) (1989): The Institution of Philosophy: A Discipline in Crisis?, La Salle, IL, Open Court.

Cremasch, Sergio, y Marcelo Dascal (1996): "Malthus and Ricardo on economic method", History of Political Economy.

- y Marcelo DASCAL (en preparación): «Methodology and thetoric in the Malthus-Ricardo controversy".

DASCAI. Marcelo (1975): "La razón y los misterios de la fe segun Leibniz», Revista Latinoamericana de Filosofia, 1: 192-226.

- (1977): "Conversational relevance», Joumal of Pragmatics, 1: 309-327.

- (1979): "Closed society, open society, abstract society», en H. Berghel, A. Huebner y E. Kohler (comps.), Wittgenstein, the Vienna Circle, and Critical Rationalism, Viena, HolderPichler-Tempsky, 253-257.

- (1983): Pragmatics and the Phitosophy of Mind, vol. 1, Amsterdam, John Benjarnins.

-- (comp.) (1985): Dialogue: An Inter-Disciplinary Approach, Amsterdam, J. Benjamins.

- (1986): "Una crítica reciente a la noción de significado literal», Crítica. Revista Hispanoamericana de Filosofia, 18 (53): 33-55.

- (1989a) «Controversies as quasi-dialogues», en E. Weigand y F. Hundsnurcher (eds.), Dialoganalyse, II, vol. 1, Tubinga, Max Niemeyer, pp. 147-159.

- (1989b): aTolerancia e interpretaçãom, Critica, 21 (62): 3-28.

- (1990a): «The controversy about ideas and the ideas of controversyn, en Gil (comp.), pp. 61-100.

- (1990b): «La arrogancia de la Razón», Isegoria, 2: 75-103.

- (1990c): «Artificial intelligence as epistemology?*, en E. Villanueva (comp.), Informationt, Semantics, and Epistemology, Oxford, Blackwell, pp. 224-241.

- (1992a): "Why does language matter to artificial intelligence?", Minds and Machines, 2 (2): 145-174.

- (1992b): «On the pragmatic structure of conversation $w_{,}$en J.R. Searle et al, (On) Searle ont Conversation (ed. e introd. de H. Parret y J. Verschueren), Amsterdam, John Benjamins, pp. 35-56. 
- (1992c): «Models of Interpretation», en M. Stamenov (ed.), Cutrent Advances in Semantic Theory, Amsterdam, John Benjamins, pp. 109-127.

- (1994): «Lenguaje y conocimiento en la filosofía modema», Enciclopedia Iberoamericana de Filosofí, vol. 6, Del Renacimiento a la Ilustración, I, Madrid, Trotta/CSIC, pp. 15-51.

- (1995a): "The debate on the primacy of thinking or speaking", en M. Dascal, D. Gerhardus, K. Lorenz y G. Meggle (comps.), Philosophy of Ianguage - An Intemational Handbook of Contemporary Research, vol. 2, Berlín / Nueva York, De Gruyter, pp. 1.024-1.040.

- (1995b): "Cognitive science in the philosopher's mill», Pragmatics \& Cognition, 3 (1): 133145.

- (en imprenta a): «The balance of reason», en D. Vanderveken (comp.), Logic, Language, and Thought, Oxford University Press.

- (en imprenta b): «The Beyond Enterprises, en J. Stewart (comp.), Beyond the Symbol Model, Albany, NY, SUNY Press.

- (en imprenta c): "La pragmática y las intenciones comunicativas», Enciclopedia lberoamericana de Filosofia, Fitosofia del Lenguaje, Madrid, Trotta/CSIC.

$\rightarrow$ y Sergio Cremascar (en preparación): "Malthus and Ricardo: A study in the pragmatics of scientific controversy".

- y Tamar KATREI (1977): "Between semantics and pragmatics: the two types of 'but" Hebrew 'aval' and 'ela's, Theoretical Linguistics, 4: 143-172.

-, y Tamar KATRIEL (1979): "Digressions: a study in conversational coherence», PTL - Poetics and Theory of Literature, $4: 203-232$.

-, y Yaron SEnDERowicz (1992): «How pure is pure reason? Language, empirical concepts, and empirical laws in Kant's theory of knowledgen, Hisfoire, Epistemologie, Langage, 14 (2): 129-152.

- y Elda WeIzMaN (1987): «Contextual explotation of interpretation clues in text understanding: an integrated modelm, en J. Verschueren y M. Bertucelli-Papi (eds.), The Pragmatic Perspective - Selected Papers from the 1985 Intemational Pragmatics Conference, Amsterdam, John Benjamins, pp. 31-46.

DAVIDSON, Donald (1974): "On the very idea of a conceptual scheme», en Davidson (1984), pp. 183-198.

- (1978): "What metaphors mean», en Davidson (1984), pp. 245-264.

- (1984); Inqtiries into Truth and Interpretation, Oxford, Oxford University Press:

- (1985). "Communication and convention", en Dascal (comp.), pp. 11-25.

ENGel HaRdT Jr., y Arthur L. CAPLAN (1987): "Patterns of controversy and closure: the interplay of knowledge, values, and political forces», en Engelhardt Jr. y Caplan (comps.), pp. 1-23.

-.. H. TRISTRaM, y Arthur L. Caplan (comps.) (1987): Scientific Controversies: Case Studies in the Resolution and Closure of Disputes in Science and Technology, Cambridge, Cambridge University Press.

FEYERABEND, Paul (1980): "Consolations for the specialist", en Lakatos y Musgrave (comps.), pp. 197-230.

Frankel, Henry (1987): «The continental drift debate», en Engelhart Jr, y Caplan (comps.), pp. 203-248.

Gu, Fernando (1985); «Science and controversy», en Dascal (comp.), pp. 353-365.

- (1990a): Prove: Attraverso la Nozione di Prova/Dimostrazione, Milán, Jaca Book.

- (comp.). (1990b): Controvérsias Cientificas e Filosoficas, Lisboa, Editora Fragmentos.

Grunger, Gilles Gaston (1959): Methodologie Economique, Paris, Presses Universitaires de France.

- (1968): Essai d'une Philosophie du Style, París, Armand Collin.

- (1979), Langages et Epistémologic, Paris, Klincksieck.

- (1985): «Discussing or convincing: An approach towards a pragmatical study of the language of sciences, en Dascal (comp.), pp. 339-351.

Gross, Alan G. (1990): The Rhetoric of Science, Cambridge, MA, Harvard University Press.

- (1993): aRhetorical imperialism in sciencen, College Enghish, 55 (1); 82-87. 
Hackns, lan (1981a): «Lakatos's philosophy of sciences, en Hacking (comp.), pp. 128-143.

- (comp.) (1981b): Scientific Revolutions, Oxford, Oxford University Press.

HESSE, Mary (1966): Models and Analogies in Science, Notre Dame, IN, University of Notre Dame Press.

KaNT, Immanuel (1952): Crtitca de la Razón Pura (trad. de J. del Perojo), Buenos Aires, Sopena $[=\mathrm{CRP}]$.

Kuyn, Thomas S. (1962); The Structure of Scientific Revolutions, Chicago, The University of Chicago Press.

- (1970): "Reflections on my critics», en Lakatos y Musgrave (comps.), pp. 231-278.

- (1977): The Essential Tension, Chicago, The University of Chicago Press.

Lakaros, Imre (1970): "Falsification and the methodology of scientific research programmes", en Lakatos y Musgrave (comps.), pp. 91-196.

- (1981): "History of science and its rational reconstructions» [1970], en Hacking (comp.), pp. $107-127$.

-, y Alan Musgrave (comps.) (1970): Criticism and the Growth of Knowledge, Cambridge, Cambridge University Press.

LerBNIz, Gottfried Willhelm (1982): Vorausedition zur Reihe VI - Phitosophische Schriftert, Münster, Leibniz-Forschungstelle [= VOR].

MCCLoskey, Donald N. (1994a); Knowledge and Persuasion in Economics, Cambridge, Cambridge University Press.

- (1994b): «How economists persuade», Joumal of Economic Methodology. 1 (1): 15-32.

McMulur, Eman (1987): «Scientifical controversy and its termination", en Engelhardt Jr* y Caplan (comps.), pp. 49-91.

MALONEY, John (1994): "Economic method and economic rhetoric", Joumal of Economic Methodology, 1 (2): 253-267.

MAYER, Thomas (1994): "Why is there so much disagreement among economists?», Joumal of Economic Methodology, 1 (1): 1-13.

MENDEISOHN, Everett (1987): "The political anatomy of controversy in the sciences", en Engelhardt Jr: y Caplan (comps.), pp. 93-124.

PENA, Lorenzo (1991): "Contradictions and paradigms: A paraconsistent approach", en $M$. Dascal (comp.), Cultural Relativism and Philosophy: North and Latin American Perspectives, Leiden, Brill, pp. 29-56.

PERA, Marcello (1991): Scienza e Retorica, Roma/Bari, Laterza.

Poppes, Karl (1970): «Normal science and its dangers», en Lakatos y Musgrave (comps.), pp. $51-58$

- (1981): «The rationality of scientific revolutions" [1975], en Hacking (comp.), pp. 80-106.

- (1987): "Campbell on the evolutionary theory of knowledgem, en Radnitzy y Bartley III (comps.), pp. 115-120.

RADNITzKY, Gerard, y W.W. BARTLEY III (comps.) (1987): Evolutionary Epistemology, Theon of Rationality, and the Sociology of Knowledge, La Salle, IL, Open Court.

Rucardo, David (1951-1973); The Works and Correspondence, 11 vols. (ed. de P. Sraffa con la colaboración de M.H. Dobb), Cambridge, Cambridge University Press [= WC]

Romano, Carlin (1989): "The illegality of philosophy", en Cohen y Dascal (comps.). pp. 199216.

STICH, Stephen (1994): «Naturalizing epistemology: Quine, Simon and the prospects for pragmatism», en C. Hookway y D. Peterson (comps.), Philosophy and Cognitive Science, Cambridge, Cambridge University Press, pp. 1-17.

Thagard, Paul (1992): Conceptual Revolutions, Princeton, Princeton University Press. 